\title{
Heterochromatin formation in Drosophila requires genome-wide histone deacetylation in cleavage chromatin before mid-blastula transition in early embryogenesis
}

\author{
Matthias Walther ${ }^{1,2} \cdot$ Sandy Schrahn ${ }^{1} \cdot$ Veiko Krauss $^{3} \cdot$ Sandro Lein $^{1} \cdot$ Jeannette Kessler $^{1} \cdot$ Thomas Jenuwein $^{2}$. \\ Gunter Reuter ${ }^{1}$
}

Received: 4 September 2019 / Revised: 13 December 2019 / Accepted: 2 January 2020 / Published online: 16 January 2020

(C) The Author(s) 2020

\begin{abstract}
Su(var) mutations define epigenetic factors controlling heterochromatin formation and gene silencing in Drosophila. Here, we identify SU(VAR)2-1 as a novel chromatin regulator that directs global histone deacetylation during the transition of cleavage chromatin into somatic blastoderm chromatin in early embryogenesis. SU(VAR)2-1 is heterochromatin-associated in blastoderm nuclei but not in later stages of development. In larval polytene chromosomes, SU(VAR)2-1 is a band-specific protein. SU(VAR)2-1 directs global histone deacetylation by recruiting the histone deacetylase RPD3. In Su(var)2-1 mutants H3K9, H3K27, H4K8 and H4K16 acetylation shows elevated levels genome-wide and heterochromatin displays aberrant histone hyperacetylation. Whereas H3K9me2- and HP1a-binding appears unaltered, the heterochromatin-specific H3K9me2S10ph composite mark is impaired in heterochromatic chromocenters of larval salivary polytene chromosomes. SU(VAR)2-1 contains an NRF1/ EWG domain and a C2HC zinc-finger motif. Our study identifies SU(VAR)2-1 as a dosage-dependent, heterochromatininitiating SU(VAR) factor, where the SU(VAR)2-1-mediated control of genome-wide histone deacetylation after cleavage and before mid-blastula transition (pre-MBT) is required to enable heterochromatin formation.
\end{abstract}

Keywords Heterochromatin · Histone deacetylation · Mid-blastula transition · Drosophila melanogaster

\section{Introduction}

The stochastic silencing of a gene when juxtaposed to heterochromatic regions by rearrangements or transposition in position-effect variegation (PEV) has been successfully used in Drosophila to reveal epigenetic factors that favor the establishment of either euchromatic or heterochromatic domains (for a review see Girton and

Electronic supplementary material The online version of this article (https://doi.org/10.1007/s00412-020-00732-x) contains supplementary material, which is available to authorized users.

Gunter Reuter

reuter@genetik.uni-halle.de

1 Developmental Genetics, Institute of Biology, Martin Luther University Halle, Weinbergweg 10, 06120 Halle/S., Germany

2 Max Planck Institute of Immunobiology and Epigenetics, Stübeweg 51, 79108 Freiburg, Germany

3 Cluster of Excellence in Plant Science (CEPLAS), University of Cologne, Biocenter, 50674 Cologne, Germany
Johansen 2008; Elgin and Reuter 2013). Classical genetic screens in Drosophila for modifiers of PEV estimate that about 200 independent loci enhance or suppress PEV, the so-called E(var) and Su(var) genes. The few molecularly defined E(VAR) proteins exert their function mainly at euchromatic regions (Farkas et al. 1994; DeRubertis et al. 1996; Dorn et al. 1993a; Weiler 2007; Lloret-Llinares et al. 2008). In contrast, SU(VAR) factors stabilize the repressed chromatin state and are thus often associated with heterochromatic regions of Drosophila (Elgin and Reuter 2013). Of the estimated $100 \mathrm{Su}$ (var) loci, only about $20 \%$ have so far been defined by positional cloning or candidate gene analysis. Amongst those are several prominent factors in the establishment and maintenance of heterochromatin, e.g. the H3K9 methyltransferase (KMTase) SU(VAR)3-9 (Tschiersch et al. 1994; Rea et al. 2000; Schotta et al. 2002), the $\mathrm{H} 3 \mathrm{~K} 9 \mathrm{me} 2 / 3$-binding protein $\mathrm{SU}(\mathrm{VAR}) 2-5$ (HP1a) (Eissenberg et al. 1992; Lachner et al. 2001; Fischle et al. 2003) and the H3K4 demethylase SU(VAR)3-3 (LSD1) (Rudolph et al. 2007; Di Stefano 
et al. 2007). In addition, mutations in a number of chromatin regulators, including the H4K20 KMTase Suv4-20 (Schotta et al. 2004), the Jumonji C domaincontaining protein Jarid2/LID (Sasai et al. 2007), or the protein phosphatase PP1 (Baksa et al. 1993), modify PEV variegation, indicating a role in heterochromatin formation. Although most of these are SU(VAR) factors, genetic analysis suggests an equal number of $S u(v a r)$ and E(var) genes (Dorn et al. 1993b). Combined, these studies revealed the molecular identity of about 40 chromatin factors in Drosophila, many of which are conserved in the mammalian system (Fodor et al. 2010). Thus, the identification of novel Su(var) genes has farreaching implications in providing insight into the molecular basis of Drosophila heterochromatin, and indicates that many of the newly characterized pathways might also operate in other eukaryotes (Grewal and Jia 2007; Allshire and Madhani 2017).

In addition to their role in constitutive heterochromatin, many SU(VAR) factors have functions in other chromatin-dependent processes such as genome stability (Janssen et al. 2018), reprogramming/pluripotency (Soufi et al. 2012; Lu et al. 2014), transposon silencing (Karimi et al. 2011; Bulut-Karslioglu et al. 2013) and epithelial-mesenchymal transition in (EMT)/tumor progression (Ting et al. 2011; Millanes-Romero et al. 2013). Thus, the identification of novel Su(var) genes has the potential not only to provide further mechanistic insights into the epigenetic roles of SU(VAR) factors, but also to reveal the molecular pathways underpinning new functions of heterochromatin.

Here, we describe a novel SU(VAR) factor with a fundamental role in heterochromatin formation during Drosophila development. The Su(var)2-1 gene encodes a NRF1-domain protein with differential chromatin association throughout development. It is heterochromatinassociated in early blastoderm but later in development, it is an abundant band protein. SU(VAR)2-1 controls development-specific histone deacetylation at pre-midblastula by recruiting the RPD3 (HDAC1) histone deacetylase. Furthermore, SU(VAR)2-1 is required for establishment of the heterochromatin-specific H3K9me2S10phos double histone modification mark. The SU(VAR)2-1 protein has a crucial role in global chromatin reorganization at pre-MBT by controlling genome-wide histone deacetylation maternally, preceding differential establishment of euchromatic and heterochromatic chromatin domains. SU(VAR)2-1 is thus the first factor to be identified, which is involved in epigenetic processes of chromatin transition after cleavage. This discovery will facilitate analysis of the so far uncharacterized epigenetic processes preceding differentiation of alternative chromatin states in the blastoderm.

\section{Materials and methods}

\section{Drosophila culture, stocks and genetic analysis}

Flies were reared on Drosophila standard medium at $25^{\circ} \mathrm{C}$. Chromosomes and mutations not noted here are described in FlyBase (http://flybase.org). The $\operatorname{In}(1) w^{m 4 h}$ rearrangement was used for the analysis of PEV. For P element-mediated transformation, we used the $w^{1118}$ strain from the Bloomington Drosophila Stock Center.

The 20 Su(var)2-1 mutants (Fig. 1 and Supplementary Table S1) were isolated by their strong dominant suppressor effect on white gene silencing in the sensitized $E$ (var) background of $\operatorname{In}(1) w^{m 4} ; T(2 ; 3) a p^{X a}+\operatorname{In}(2 L) C y$, ap ${ }^{X a} C y E($ var $) 3-$ $1^{01}$ after EMS (2.5 mM) mutagenesis (Reuter et al. 1986). The $\mathrm{Su}$ (var)2-1 alleles $2-1^{210}, 2-1^{214}$ and $2-1^{215}$ were isolated by Sinclair et al. (1992).

Deficiencies $D f(2 L) B S C 144$ and $D f(2 L) B S C 206$ were obtained from the Bloomington Drosophila Stock Center and deficiencies $D f(2 L) E D 721$ and $D f(2 L) E D 729$ were generated according to the method described in Ryder et al. (2007). In $D f(2 L) S u(v a r) 2-1^{d s}$, a knock-out of $S u$ (var)2-1 was generated by the Cas $9 / \mathrm{sgRNA}$ system according to the method described by Gratz et al. (2013). The $P\{S g s 3-G A L 4\}$ salivary gland cell-specific GAL4 driver was obtained from the Bloomington Drosophila Stock Center.

The transgenes $P\left\{w^{+}\right.$UAST-attB-Strep-Su(var)2-1-V5$3 \times F L A G\}, P\{F l y F o s 026029-S u(v a r) 2-1-V 5-3 \times F L A G\}$ and $P\left\{w^{+} U A S-S u(v a r) 2-1-E G F P\right\}$ were generated for $S u(v a r) 2-$ 1 mutant rescue and expression of SU(VAR)2-1 fusion proteins containing antibody tags (Supplementary Table S1). The $P\left\{w^{+}\right.$UAST-attB-Strep-Su(var)2-1-V5-3xFLAG $\}$and $P\{$ FlyFos026029-Su(var)2-1-V5-3xFLAG $\}$ rescue transgenes express SU(VAR)2-1 under the control of the endogenous Su(var)2-1 promoter and were generated according to the method described by Ejsmont et al. (2009) and Bischof et al. (2007). $\mathrm{pP}\left\{\mathrm{w}^{+}\right.$UAST-attB-Strep-Su(var)2-1-V5-3xFLAG $\}$ was injected into attP-ZH-51D and pP $\{$ FlyFos026029$\mathrm{Su}($ var)2-1-V5-3xFLAG 3 into attP2 embryos. The attP-ZH$51 D$ [\#24483] and attP2 [\#8622] fly lines were received from the Bloomington Drosophila Stock Center. In $P\left\{w^{+} U A S\right.$ Su(var)2-1-EGFP\} the coding sequence of Su(var)2-1$E G F P$ was placed under the control of the $U A S$ promoter.

\section{Molecular cloning and transformation of wild-type rescue constructs}

The genomic full-length wild-type $S u$ (var)2-1 gene was amplified with primers GGGGACAAGTTTGTACAAAA AAGCAGGCTCAAAATATTTATTTAGACGACTCCCAA ACAC and AGGGGACCACTTTGTACAAGAAAGCT GGGTGAGAAGTTAAATCAATGGAAATTAT-ACGCC by PCR and cloned via the Gateway system into the pDONR- 
a

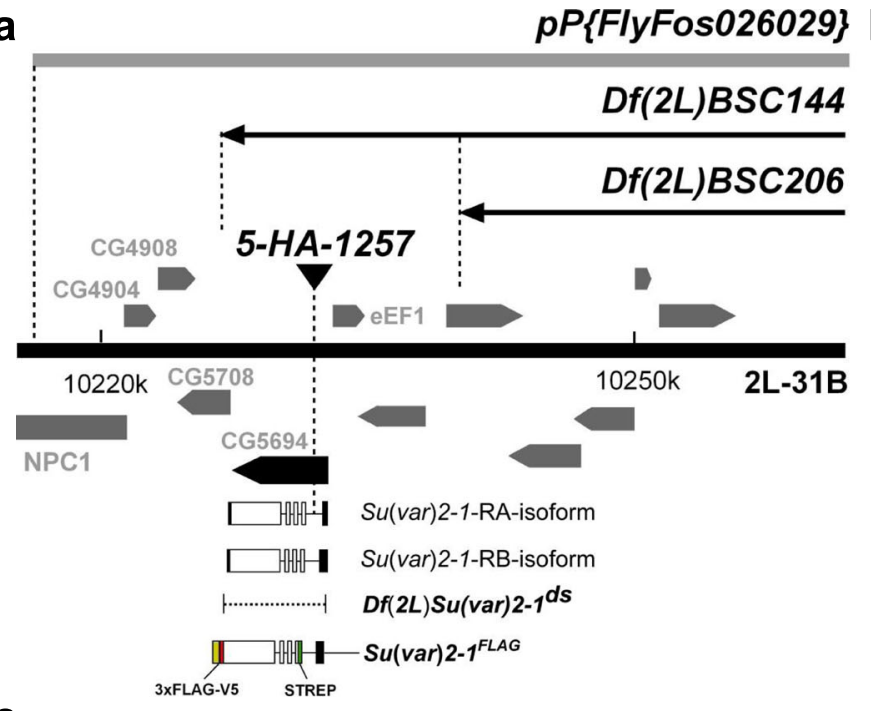

C

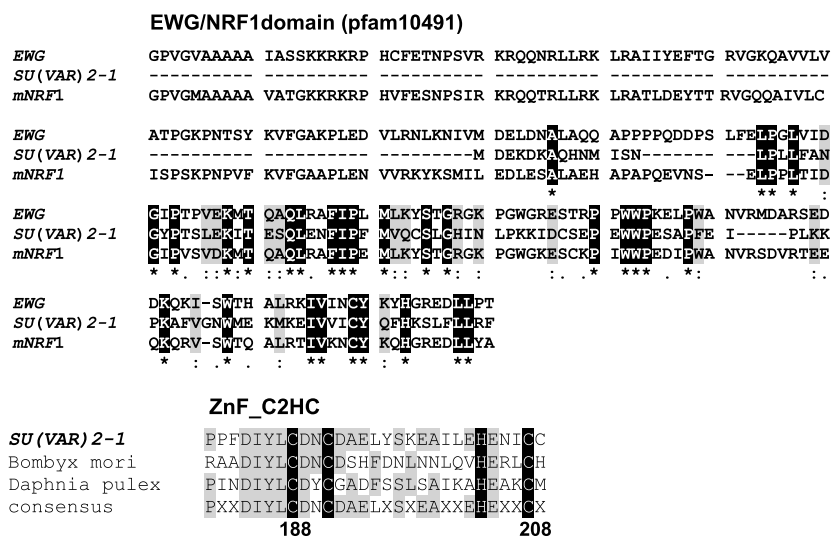

Fig. 1 Su(var)2-1 encodes a NRF domain protein with a $\mathrm{C} 2 \mathrm{HC}$ zincfinger motif. a Cytogenetic mapping of $\mathrm{Su}(\mathrm{var}) 2-1$ within region $31 \mathrm{~B}$ in chromosome arm $2 \mathrm{~L}$ between the distal breakpoints of $D f(2 L) B S C 144$ and $D f(2 L) B S C 206$. The $p P\{R S 5\} 5-H A-1257$ element inserted within the first intron of CG5694 and a CRISPR/Cas9 induced deletion of CG5694 $\left\{D f(2 L) S u(v a r) 2-1^{d s}\right\}$ are allelic to Su(var)2-1 mutations. The $p P\{F l y F o s 026029\}$ and P\{UAST-attB Strep-Su(var)2-1-V5$3 x F L A G\}$ transgenes rescue $S u(v a r) 2-1$ mutations. b Molecularly defined Su(var)2-1 mutations including in total 15 stop or frameshift mutations (*) and 7 point mutations. The $S u$ (var) $2-1$ alleles $2-1^{210}, 2-1^{214}$ and $2-1^{215}$

zeo vector. The coding sequence for a Strep-Tag-II (Stratagene) was added to the cloned genomic Su(var)2-1 construct using site directed mutagenesis with the primer pair AGTGACAAATGGCTTGGAGCCACCCGCAGTTC GAAAAAGATGAAAAAGAT and ATCTTT.

TTCATCTTTTTCGAACTGCGGGTGGCTCCAAG CCATTTGTCACT (Supplementary Table S2). The modified Step-Tag-II construct was cloned into a modified Gatewayconverted pUAS-TattB-V5-3xFLAG vector (GenBank EF362409.1; Bischof et al. 2007) to obtain the tagged genomic rescue construct Strep-Tag-II-Su(var)2-1-V5-3xFLAG. All constructs were verified by DNA sequence analysis. Transgenic flies were generated using the $\varphi \mathrm{C} 31$-based integration into the ZH-attP-51D landing site (Bischof et al. 2007).

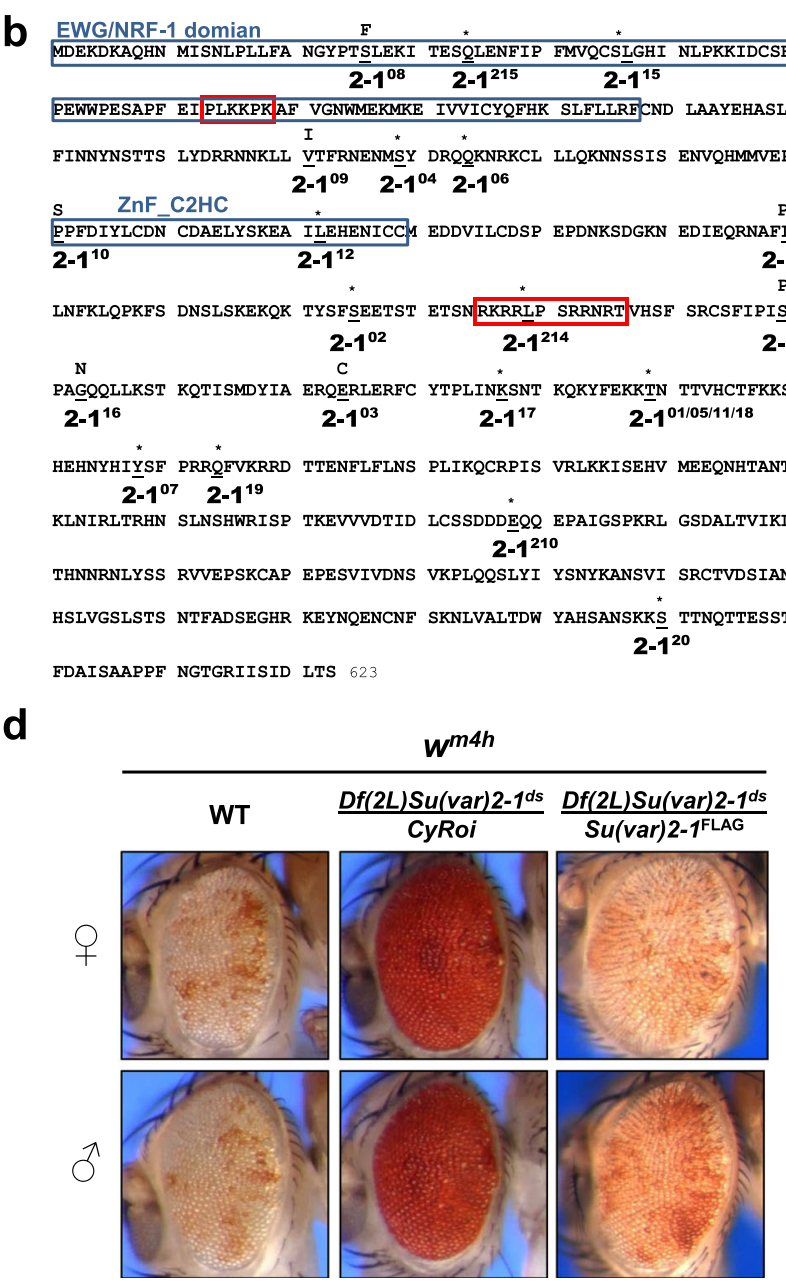

were isolated by Sinclair et al. 1992. The SU(VAR)2-1 protein contains two putative nuclear localization signals (red boxes). $\mathbf{c}$ In the SU(VAR)2$1 \mathrm{~N}$-terminus about 100 amino acids show homology to the C-terminal half of the NRF1/EWG domain of Drosophila ERECT WING (EWG) and mammalian NRF1 proteins. In addition, SU(VAR)2-1 contains a C2HC motif between amino acids 188-208. d Phenotypic rescue of Su(var)2-1 mutants by P\{UAST-attB Strep-Su(var)2-1-V5-3xFLAG $\}$ expressing a fusion protein with a $\mathrm{N}$-terminal STREP and C-terminal V53 XFLAG tag under the endogenous Su(var)2-1 promoter (Abbreviated $\mathrm{Su}($ var $) 2-1^{\text {FLAG }}$ )

\section{CRISPR/Cas9-mediated HDR replacement of Su(var)} 2-1

The target DNA sequences selected for the CRISPR RNAguided Cas9 nuclease were predicted using software (http:// targetfinder.flycrispr.neuro.brown.edu/). The targeting sequence was cloned under the control of the U6 promoter by annealing phosphorylated oligonucleotides to the pU6BbsI-chiRNA plasmid at the BbsI restriction sites. Donor templates containing $\mathrm{Su}$ (var)2-1 homology arms (about $1 \mathrm{~kb}$ ) were amplified by standard PCR methods and introduced into the pHD-DsRed vector. To generate the $S u$ (var)2-1 replacement donor pHD-DsRed ${ }^{\text {Su(var)2-1 }}$, regions of homology flanking the $\mathrm{S} 1$ and $\mathrm{S} 2$ cleavage sites of around $1 \mathrm{~kb}$ in length 
were amplified (Phusion polymerase, Thermo Scientific) and incorporated via EcoRI and NotI restriction sites at the 5'-end and via PstI and XhoI at the $3^{\prime}$ - end (Supplementary Table S2) into the pHD-DsRed donor-vector (Gratz et al. 2014). In order to generate of targeting chiRNAs (Supplementary Table S2), the target-specific sequences for $\mathrm{Su}$ (var)2-1 were synthesized as 19 bp-phosphorylated oligonucleotides, which were annealed and ligated into the BbsI restriction sites of pU6BbsI-chiRNA vector (Gratz et al. 2013). The pU6-BbsIchiRNA vector containing the targeting gRNA $(100 \mathrm{ng} / \mu \mathrm{l})$ and the pHD-DsRed vector containing the donor templates $(450 \mathrm{ng} / \mu \mathrm{l})$ were co-injected as high-quality DNA into embryos produced by $M\{$ vas-Cas 9$\} Z H-2 A / F M 7 c$ flies, which express Cas9 in the germline. Positive $\mathrm{Su}$ (var)2-1 knock-out lines were selected by screening for the DsRed marker.

\section{FISH analysis and immunohistochemistry}

For FISH analysis of cycle 14 embryos after fixation with formaldehyde, the protocol of Phalke et al. (2009) was used with the following modifications: for preparation of digoxigenin-labeled probes, the desired sequence was amplified directly from the genomic DNA by using primers specific for the 359 bp satellite repeat, Invader 4 LTRs, the R1 element and the distal X chromosome respectively. Images were processed using the image software supplied (Zeiss, Germany). Primer sequences are listed in Supplementary Table S2.

\section{Polytene chromosome fixation and immunostaining}

Salivary glands were dissected from 3rd instar larvae. Preparation of polytene chromosomes was performed as described previously (Silver et al. 1978) with the following modifications: salivary glands were dissected in $0.7 \% \mathrm{NaCl}$, fixed for $4 \mathrm{~min}$ and squashed in 55\% (v/v) acetic acid/3\% (v/v) formaldehyde. Chromosomes were incubated after blocking with 5\% (w/v) skimmed milk powder in PBST (PBS with $0.05 \%$ Triton) with the indicated monoclonal or polyclonal antibodies $(1 \mu \mathrm{g} / \mathrm{ml})$ at $4{ }^{\circ} \mathrm{C}$ overnight, followed by incubation with fluorescently labeled secondary antibodies (1:250) for $2 \mathrm{~h}$ at $37^{\circ}$. For the list of antibodies, see Table S3. DNA of labeled preparation was stained with DAPI or Hoechst and mounted in VECTASHIELD antifade mounting medium. Preparations were examined with confocal laser-scanning microscopy (LSM 780, Zeiss) and processed with ZenPro software (Zeiss).

\section{Embryo fixation and immunostaining}

Drosophila embryos were collected on apple juice agar plates, washed $(0.7 \% \mathrm{w} / \mathrm{v} \mathrm{NaCl}, 0.05 \% \mathrm{w} / \mathrm{v}$ Triton-X 100) into mesh baskets, and dechorinated in $12 \%(\mathrm{w} / \mathrm{v})$ bleach for $2 \mathrm{~min}$ at room temperature. Dechorinated embryos were fixed with the boiling fix method as described (Rothwell and Sullivan 2000). Dechorinated and fixed embryos were then devitellenized in a 1:1 mixture of methanol-heptane. Dechorinated, fixed, devitellenized and dehydrated embryos were initially rehydrated in a series of increasing PBTA: methanol mixtures (PBS with $0.1 \% \mathrm{w} / \mathrm{v}$ Triton, $0.05 \% \mathrm{w} / \mathrm{v}$ BSA). After following rehydration in PBTA for 25 min embryos were then blocked in PBTA supplemented with $2 \%(\mathrm{w} / \mathrm{v})$ skimmed milk powder and $3 \%(\mathrm{w} / \mathrm{v})$ normal donkey serum for $1 \mathrm{~h}$ at room temperature. Prepared embryos were then incubated with the indicated primary antibodies $(1 \mu \mathrm{g} / \mathrm{ml})$ overnight at $4{ }^{\circ} \mathrm{C}$ in blocking buffer. Embryos were then washed three times with PBTA for 10 min each and then incubated with the appropriate fluorescently labeled secondary antibody (1:250) for $1 \mathrm{~h}$ in a dark room at $37{ }^{\circ} \mathrm{C}$. Embryos were washed after incubation with secondary antibody again five times with PBTA for $10 \mathrm{~min}$ each. Hoechst-DNA-dye was added to the third wash. Finally, stained embryos were mounted on glass slides in VECTASHIELD antifade mounting medium or PBS supplemented with $50 \%(\mathrm{w} / \mathrm{v})$ glycerol. Preparations were examined with confocal laser-scanning microscopy (LSM-780, Zeiss) and processed with ZenPro software (Zeiss).

\section{Ovary fixation and immunostaining}

Drosophila ovaries of 2- or 3-day-old, well-fed female flies were dissected by hand in PBS buffer. The sheath surrounding the ovaries was removed and both pairs of ovaries were fixed with fixative (4\% v/v paraformaldehyde) for $15 \mathrm{~min}$. Ovaries were dissected and fixed with $4 \%(\mathrm{v} / \mathrm{v})$ paraformaldehyde for $30 \mathrm{~min}$ at room temperature. The staining procedure was performed as described (Shcherbata et al. 2004) with the following modifications: after rinsing the ovaries with PBT (PBS/ $0.2 \% \mathrm{w} / \mathrm{v}$ Triton X-100) 3 times, they were incubated with methanol, rinsed again 3 times with PBT and then rehydrated for $1 \mathrm{~h}$ with PBT on a rotating wheel. Embryos and ovaries were incubated with primary antibodies $(1: 100 / \mathrm{PBS}+1 \% \mathrm{w} / \mathrm{v}$ BSA $+0,05 \% \mathrm{w} / \mathrm{v}$ Triton X-100) overnight at $4{ }^{\circ} \mathrm{C}$ followed by incubation with Alexa Fluor 488 or 555-conjugated secondary antibody for $2 \mathrm{~h}$ at $37{ }^{\circ} \mathrm{C}(1: 100 / \mathrm{PBS}+1 \% \mathrm{w} / \mathrm{v}$ $\mathrm{BSA}+0.05 \% \mathrm{w} / \mathrm{v}$ Triton X-100). Preparations were examined by confocal laser-scanning microscopy (LSM 510 and 780; Zeiss). Images were processed using the image software supplied by the microscope manufacturer (Zeiss, Germany). Antibodies used are listed in Supplementary Table S3.

\section{RT-PCR}

Total RNA was extracted from larvae using TRIZOLTM reagent (Thermo Fisher Scientific) according to the user's manual. An aliquot $(1 \mu \mathrm{g})$ of extracted total RNA was used for cDNA synthesis using a first-strand cDNA synthesis kit (Promega). Equal amounts of cDNA samples were used in 
PCR reactions performed in triplicate in a standard PCR-cycler. Relative levels of mRNA were compared with the levels of $r p 49$ in each sample in a $1.0 \%(\mathrm{w} / \mathrm{v})$ Agarose-Gel. Primers used in RT-PCR assays are listed in Supplementary Table S2.

\section{Chromatin immunoprecipitation}

Fly heads were fixed with $1.8 \%(v / v)$ formaldehyde for $30 \mathrm{~min}$ at room temperature, homogenized, resuspended in RIPA buffer $(140 \mathrm{mM} \mathrm{NaCl}, 10 \mathrm{mM}$ Tris- $\mathrm{HCl} \mathrm{pH} 8.0,1 \mathrm{mM}$ EDTA, $1 \% \mathrm{w} / \mathrm{v}$ Triton X-100, $0.1 \% \mathrm{w} / \mathrm{v}$ SDS, $0.1 \% \mathrm{w} / \mathrm{v}$ DOC). Staged embryo chromatin immunoprecipitation (ChIP) material (cycle 11 to cycle14) was prepared according to (Loubiere et al. 2017). Crosslinked material was sonicated after preparation in $4 \mathrm{ml}$ of $10 \mathrm{mM}$ Tris- $\mathrm{HCl} \mathrm{pH} 8.0,1 \mathrm{mM}$ EDTA pH 8.0 for 30 min with a Branson 450 digital sonifier (45 cycles of $20 \mathrm{~s}$ on $-40 \mathrm{~s}$ off). The sonicated lysate was clarified by centrifugation, preabsorbed by incubation with Dynabeads $^{\mathrm{TM}}$ protein A magnetic beads (Thermo Fisher Scientific) and incubated with $7 \mu \mathrm{g}$ polyclonal antibodies $(\alpha-\mathrm{H} 3 \mathrm{~K} 9 \mathrm{ac}, \alpha-\mathrm{H} 3 \mathrm{~K} 27 \mathrm{ac}, \alpha-\mathrm{H} 4 \mathrm{~K} 16 \mathrm{ac})$ overnight at $4{ }^{\circ} \mathrm{C}$. Antibody complexes were bound to protein A-Sepharose magnetic beads. Precipitated DNA was recovered and dissolved in $150 \mu \mathrm{l}$ water. Control mock immunoprecipitations were done in parallel without antibodies. Real-time PCR analysis was performed according to previous studies (Dellino et al. 2004; Rudolph et al. 2007) and $5 \mu$ DNA from each sample was amplified in $20 \mu \mathrm{l}$ reactions with $2 \mathrm{x}$ SYBR Green Super Mix (Bio-Rad). All primer sequences used in the studies are listed in (Rudolph et al. 2007).

\section{Immunoprecipitation (GST-Trap) and immunoblotting}

Salivary glands (100) were dissected in PBS solution and transferred in $300 \mu \mathrm{l}$ of lysis buffer (20 mM HEPES pH 7,7; $1,5 \mathrm{mM} \mathrm{MgCl}_{2} ; 450 \mathrm{mM} \mathrm{NaCl} ; 30 \mathrm{mM} \mathrm{KCl} ; 0.25 \% \mathrm{w} / \mathrm{v}$ NP40; 0,1 mM EDTA; Roche protease inhibitor cocktail). Dissected glands were homogenized in the lysis buffer with an Eppendorf pestle and incubated at $4{ }^{\circ} \mathrm{C}$ on a rotating wheel for $30 \mathrm{~min}$. Extracts were diluted after incubation by adding $600 \mu$ dilution buffer $(20 \mathrm{mM}$ HEPES $\mathrm{pH} 7.7 ; 1.5 \mathrm{mM}$ $\mathrm{MgCl}_{2}$; Roche protease inhibitor cocktail) and mixed for 5 min. Diluted extract was centrifuged at $4{ }^{\circ} \mathrm{C}$ and at $12300 \mathrm{rpm}$ for $15 \mathrm{~min}$ to obtain the final salivary gland cell protein extract. Equilibrated GFP-Trap-Magnetic beads were incubated for $1 \mathrm{~h}$ at $4{ }^{\circ} \mathrm{C}$ on a rotating wheel with the salivary gland cell protein extract and afterwards washed 5 times with washing buffer (20 mM HEPES pH 7,7; $150 \mathrm{mM} \mathrm{NaCl} ; 0.1 \%$ NP40; 0.15 mM EDTA; Roche Protease inhibitor cocktail). The immune complexes were washed with lysis buffer containing $500 \mathrm{mM} \mathrm{NaCl}$ five times (total $1 \mathrm{~h}$ ) and subjected to immunoblot analysis with the indicated antibodies.
Chemicals, peptides, recombinant proteins, commercial assays and recombinant DNA used are listed in Supplementary Table S4.

\section{Phylogeny analysis}

SU(VAR)2-1-like proteins of metazoans were collected using BLASTP based on the protein database and using tBLASTn based on the transcriptome shotgun assembly and the genome assembly database of NCBI. In part, the analyses were done locally using SU(VAR)2-1 protein sequences of the most closely related arthropod species. The orthology of the hits was evaluated by reciprocal BLAST. The resulting sequences were aligned by MUSCLE (Edgar 2004) using the Unipro UGENE interface, version 1.21 (Okonechnikov et al. 2012). A tree of selected proteins was built by RAxML online (https://raxml-ng.vital-it.ch/) using the substitution matrix LG und four gamma substitution rate categories. The resulting tree was re-rooted using Mesquite 3.40 (Maddison and Maddison 2018).

\section{Results}

\section{Su(var)2-1 encodes a new type of NRF1-domain protein with a $\mathrm{C} 2 \mathrm{HC} \mathrm{ZnF}$ motif}

Su(var)2-1 belongs to a group of $S u(v a r)$ genes defined by butyrate/carnitine-sensitive mutations suggesting a function in control of histone deacetylation. The mutations are homozygous viable in females and semi-lethal in males but are lethal on media containing the inhibitors of histone deacetylation butyrate or carnitine (Reuter et al. 1982a; Dorn et al. 1986; Fanti et al. 1994). In addition, the mutations display lethal interaction with additional $\mathrm{Y}$ chromosome heterochromatin and are recessive female-sterile (Reuter et al. 1982a; Szabad et al. 1988; Dimitri and Pisano 1989). Crossover-mapping placed the gene near to the Jammed locus within chromosome region 31 on chromosome arm 2L. Su(var)2-1 displays a haplo-dependent dominant Su(var) effect, which can be rescued by a duplication of the wild-type gene allowing duplication and deficiency mapping. Mapping crosses using a series of duplications generated by recombination between two inversions (Ryder et al. 2007) placed the Su(var)2-1 gene to region 31A2-31B1. Deletion-mapping identified CG5694 as Su(var)2-1 (Fig. 1a). The P element $P$ [RS5]5-HA-1257 is inserted into the first intron of Su(var)2-1 and causes aberrant splicing at the locus resulting in a $S u(v a r) 2-1$ mutant (Fig. S1a).

We identified 20 mutant alleles from different $\mathrm{Su}$ (var) mutant screens using complementation and rescue analysis. The alleles $2-1^{210}, 2-1^{214}$ and $2-1^{215}$ were independently isolated (Sinclair et al. 1992). According to the molecular lesions 
within the $S u$ (var)2-1 gene (Fig. 1b), a total of 15 of the 23 alleles are frame-shift or stop mutations. A hot-spot of four frame-shift mutations is found within a stretch of nine adenines that encode amino acid positions 346-349 (EKKT). Seven of the isolated alleles are point mutations. All of the frame-shift/stop alleles are agametic recessive female-sterile. Of the seven point mutations, the three alleles $2-1^{03}, 2-1^{09}$ and $2-1^{10}$ are female-fertile. The other point mutations $\left(2-1^{08}, 2-\right.$ $1^{13}, 2-1^{14}$ and $2-1^{16}$ ) are female-sterile but they may lay flaccid eggs without further development. The mutant effects were evaluated in trans-heterozygotes with the CRISPR/Cas9 generated Su(var)2-1 $1^{d s}$ deletion of the locus (Fig. 1a). RT-PCR analysis showed no reduction of the $\mathrm{Su}$ (var)2-1-specific transcript in the six studied frame-shift alleles $\left(2-1^{01}, 2-1^{02}, 2-1^{04}\right.$, $2-1^{05}, 2-1^{06}$ and $2-1^{07}$ ) or the splice donor mutation $\left(2-1^{04}\right)$, thus excluding nonsense-mediated mRNA decay (Fig. S1b).

The SU(VAR)2-1 (CG5694) protein contains the Cterminal half of the NRF1/EWG (Nuclear Respiratory Factor-1/Erected Wing) domain at its N-terminus and a C2HC zinc-finger motif between amino acids 189 and 210 (Fig.1c). Two putative nuclear-targeting signals are found between amino acids 73-79 and 275-286. Mutations in the Drosophila ewg gene do not affect white gene silencing in $w^{m 4}$ (Fig. S2a). The SU(VAR)2-1 protein is conserved within insects, crustaceans and possibly also in some other Protostomata, but not in vertebrates (Fig. S2b), and shows homology with mammalian proteins through its NRF1 domain but not through its zinc-finger-containing region (Fig. $\mathrm{S} 3 \mathrm{a}$ and $\mathrm{S} 3 \mathrm{~b}$ ). Mouse Nrf1 (nuclear respiratory factor 1) is a close ortholog in mammals, which is a transcription factor whose binding is outcompeted by DNA methylation (Domcke et al. 2015).

\section{Female sterility and Su(var)2-1 mutant rescue}

We generated a series of transgenes for mutant rescue and expression of tagged SU(VAR)2-1 fusion proteins under endogenous promoter control. The $p P\{U A S T a t t B$ Strep$\mathrm{Su}$ (var)2-1-V5-3xFLAG transgene produced a fusion protein carrying an N-terminal STREP and a C-terminal V5-3xFLAG tag and was placed under the control of the endogenous Su(var)2-1 promoter. This construct rescued all Su(var)2-1 mutant phenotypes, including the dominant $\mathrm{Su}$ (var) phenotype in the eyes of $\operatorname{In}(1) w^{m 4 h}$ flies (Fig. 1d) and all phenotypic defects observed in ovarian development of Su(var)2-1 null females (Fig. S4a and Fig. S4c). Su(var)2-1 null females only develop rudimentary ovaries with egg chambers that degenerate at stage 5-6 (Fig. S4b). Female sterility is follicle celldependent (Szabad et al. 1988). Typically, the number of follicle cells covering egg chambers is significantly reduced. During egg chamber development, SU(VAR)2-1 accumulates first in the prospective egg cell nucleus and becomes more abundant in nurse cell nuclei in older egg chambers (Fig.
S4c). Effects of SU(VAR)2-1 on early embryogenesis could only be studied with the female-fertile point mutations $2-1^{03}$, $2-1^{09}$ and $2-1^{10}$. However, these alleles showed all the characteristic mutant effects on chromatin organization like Su(var)2-1 null alleles.

\section{SU(VAR)2-1 accumulates at heterochromatin in blastoderm nuclei}

Chromatin association of SU(VAR)2-1 throughout development was studied with a specific polyclonal antibody generated against a peptide containing the $322 \mathrm{C}$-terminal amino acids and, additionally, by the $P\{U A S T a t t B$ Strep-Su(var)2-1V5-3xFLAG $\}$ transgene producing a STREP-SU(VAR)2-1V5-3xFLAG fusion protein under endogenous promoter control (Fig. 2, Fig. S4c and S4d). In early cleavage, SU(VAR)2-1 is an abundant protein in syncytial nuclei. In blastoderm nuclei, polar Rabl organization of chromosomes is found with pericentric heterochromatin at the apical site and euchromatin toward the basal site (Foe et al. 1993; Rudolph et al. 2007). In early blastoderm, when heterochromatin and euchromatin formation is initiated, the SU(VAR)2-1 protein accumulated in pericentric heterochromatin at the apical site of blastoderm nuclei (Fig. 2a, b). In primordial germ-line cells, SU(VAR)21 was uniformly associated with chromatin (Fig. 2c) as in syncytial nuclei.

Heterochromatin association of SU(VAR)2-1 in blastoderm nuclei was confirmed by a study of apico-basal chromatin differentiation in blastoderm nuclei, which starts around cycle 11-13 (Fig. 3). Fluorescent in situ hybridization (FISH) with a probe specific for 359 bp satellite sequences labeled the apically located pericentromeric heterochromatin whereas a probe specific for the Invader 4 subtelomeric repeats of chromosome arms $2 \mathrm{R}$ and $3 \mathrm{R}$ identified the basally positioned telomeres (Fig. 3a). A painting probe for the distal 1A to 7A region of the $\mathrm{X}$ chromosome (Fuchs et al. 1998) further confirmed the suggested centromere-apical and telomerebasal orientation of chromosomes (Fig. 3a). A FISH probe for the non-LTR R1 retrotransposon, which forms a repeat cluster distal to the rDNA locus in the $\mathrm{X}$ chromosome (Tartof et al. 1984), marked the border region between heterochromatin and euchromatin (Fig. 3a). Staining for the centromere-specific protein CID showed the most apical positioning of centromeres in blastoderm nuclei (Fig. 3b). Immunostaining for H3K9me2 and the heterochromatin protein HP1a labeled the apically located pericentromeric heterochromatin (Fig. 3b). Euchromatic marks like H3K9ac, H3K4me2, H3K4me3 and H3K27me3 were uniformly spread from the border of heterochromatin toward the basal side of the nuclei (Fig. 3c).

The SU(VAR)2-1 protein in blastoderm nuclei was enriched, like the typical heterochromatic histone marks at the apically located pericentromeric heterochromatin (Fig. 
a

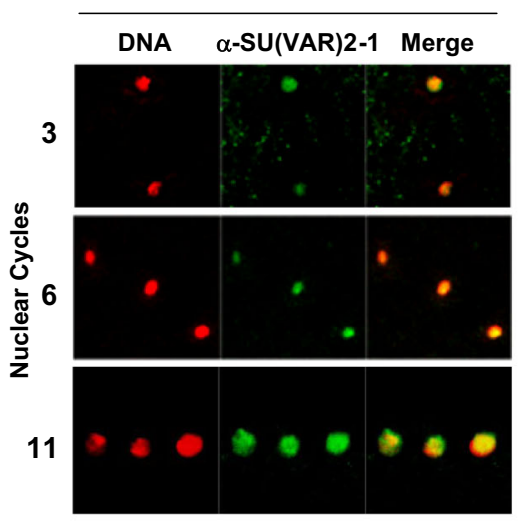

C

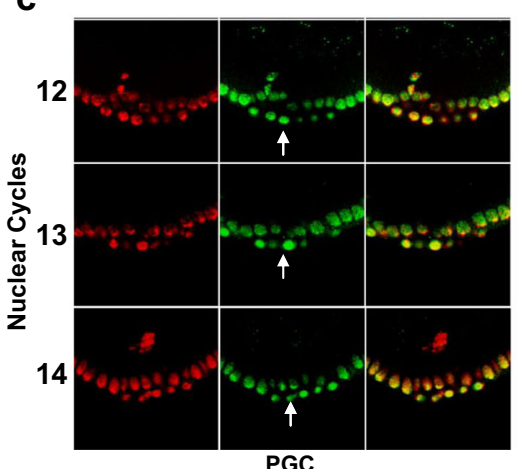

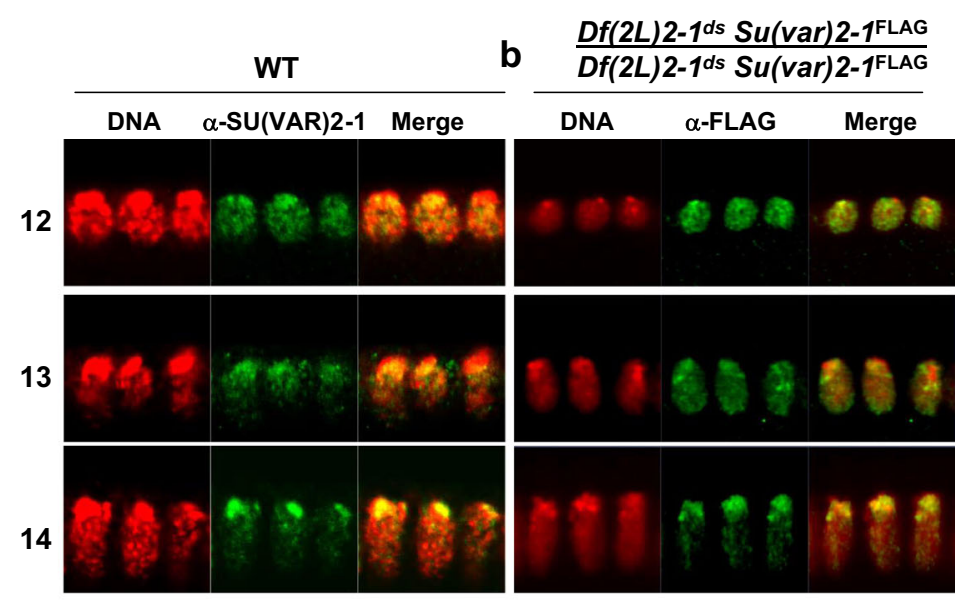

d

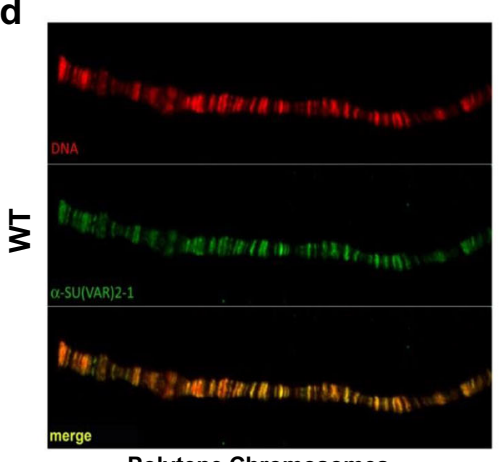

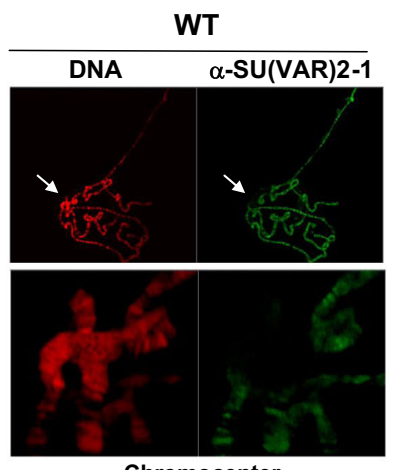

Chromocenter
Fig. $2 \mathrm{SU}(\mathrm{VAR}) 2-1$ is heterochromatin-associated in blastoderm nuclei but is a band-specific protein in polytene chromosomes. a SU(VAR)2-1 is an abundant chromatin protein in syncytial nuclei. At blastoderm cycles 11 to 14 , the SU(VAR)2-1 protein preferentially associates with heterochromatin at the apical pole as shown for the endogenous protein (SU(VAR)2-1-specific polyclonal antibody) and in $\mathbf{b}$ for the STREPSU(VAR)2-1-V5-3xFLAG fusion protein (monoclonal FLAG

$3 b)$, whereas in later embryogenesis during gastrulation SU(VAR)2-1 showed a rather uniform nuclear distribution (Fig. 3d).

Studies of larval polytene chromosomes revealed that SU(VAR)2-1 is found over bands and not in chromocenter heterochromatin (Fig. 2d). The developmentally specific heterochromatin accumulation of SU(VAR)2-1 in blastoderm nuclei when heterochromatin is established suggests that the protein is involved in initiation of heterochromatin formation during early embryogenesis. SU(VAR)2-1 is observed first in syncytial nuclei associated with all chromatin, then in blastoderm nuclei where it accumulated at pericentric heterochromatin. Later it leaves heterochromatin, and in polytene chromosomes binds the euchromatic bands and is excluded from the chromocenter (Fig. 2e). This suggests that SU(VAR)2-1 is mostly associated with euchromatin in somatic cell nuclei.

$\mathrm{Su}$ (var) 2-1 mutations display a strong dominant suppressor effect on all PEV rearrangements tested (Reuter et al. 1982b) and $w^{m 4 h} ;$ Su(var) 2-1 mutant flies express a uniformly red-eye phenotype (Fig. 1d). The suppressor effect of Su(var)2-1
Antibody). c In contrast to somatic blastoderm cells where SU(VAR)21 is preferentially in prospective heterochromatin the protein shows uniform chromatin association in primordial germ line stem cell nuclei (arrow). d In larval salivary gland polytene chromosomes SU(VAR)2-1 is a band-specific protein and not found in chromocenter heterochromatin (arrows)

mutations is as strong as a $\mathrm{Su}(\mathrm{var}) 3-9$ null mutations, which result in a complete loss of heterochromatin indexing by H3K9me2 (Schotta et al. 2002).

\section{SU(VAR)2-1 loss does not alter H3K9me2 but impairs the composite $\mathrm{H} 3 \mathrm{~K} 9 \mathrm{me2S} 10 \mathrm{ph}$ mark at pericentric heterochromatin}

In $S u(v a r) 2-1$ mutant homozygotes, we examined immunocytologically $\mathrm{H} 3 \mathrm{~K} 9 \mathrm{me} 2$ indexing of heterochromatin in larval salivary gland chromosomes and used ChIP analysis in adult heads. Interestingly, loss of a functional SU(VAR)2-1 protein did not interfere with $\mathrm{H} 3 \mathrm{~K} 9 \mathrm{me} 2$ indexing of chromocenter heterochromatin in larval salivary gland polytene chromosomes (Fig. 4a). ChIP analysis of adult heads showed no reduction of $\mathrm{H} 3 \mathrm{~K} 9 \mathrm{me} 2$ at the heterochromatic $359 \mathrm{bp}$ satellite sequences and no reduction of $\mathrm{H} 3 \mathrm{~K} 9 \mathrm{me} 2$ along the whiteroughest euchromatic region juxtaposed to pericentric heterochromatin in $w^{m 4}$ (Fig. 4b). These results suggest that SU(VAR)2-1 functions independently of SU(VAR)3-9- 

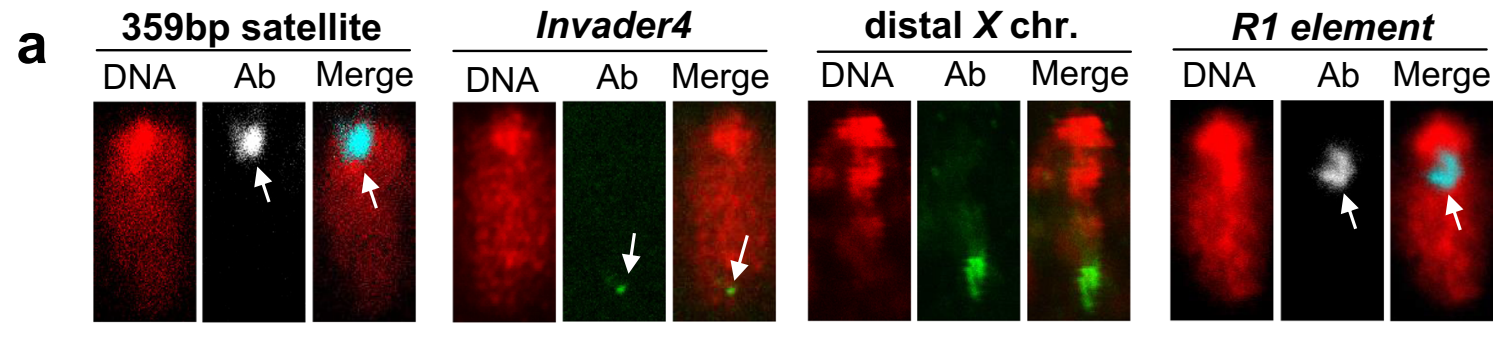

b
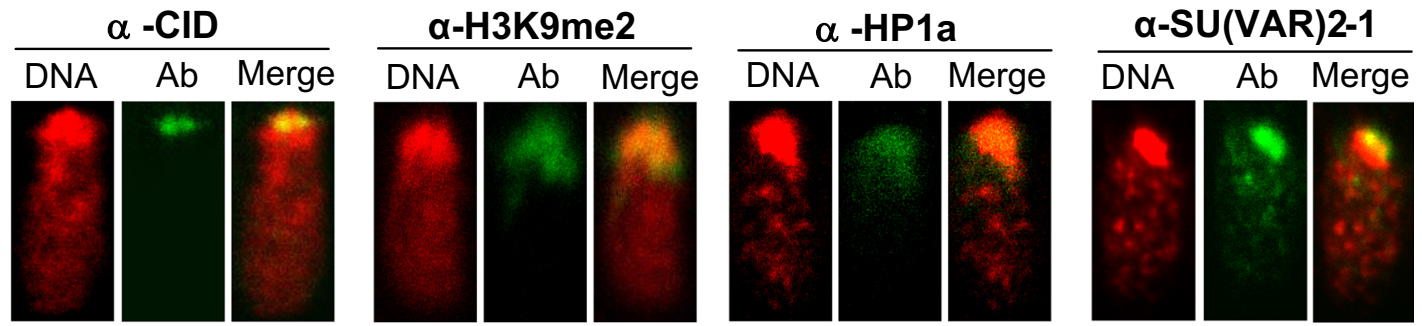

C
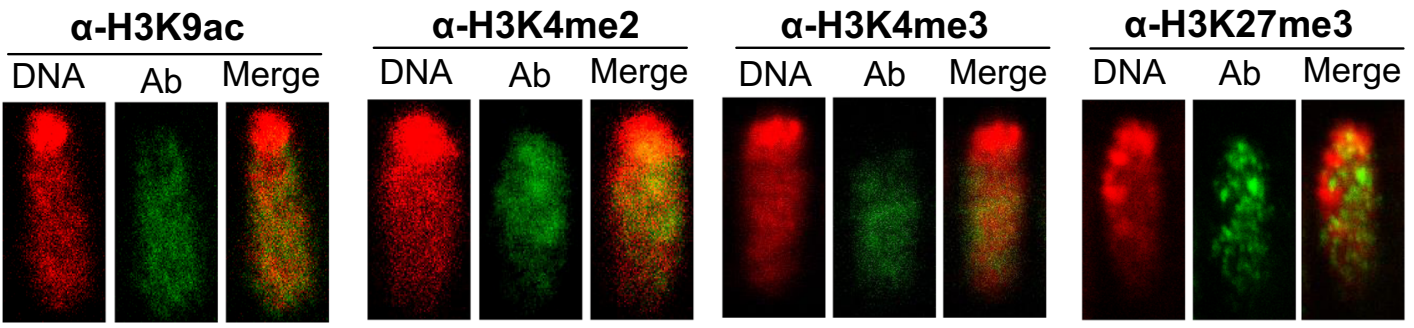
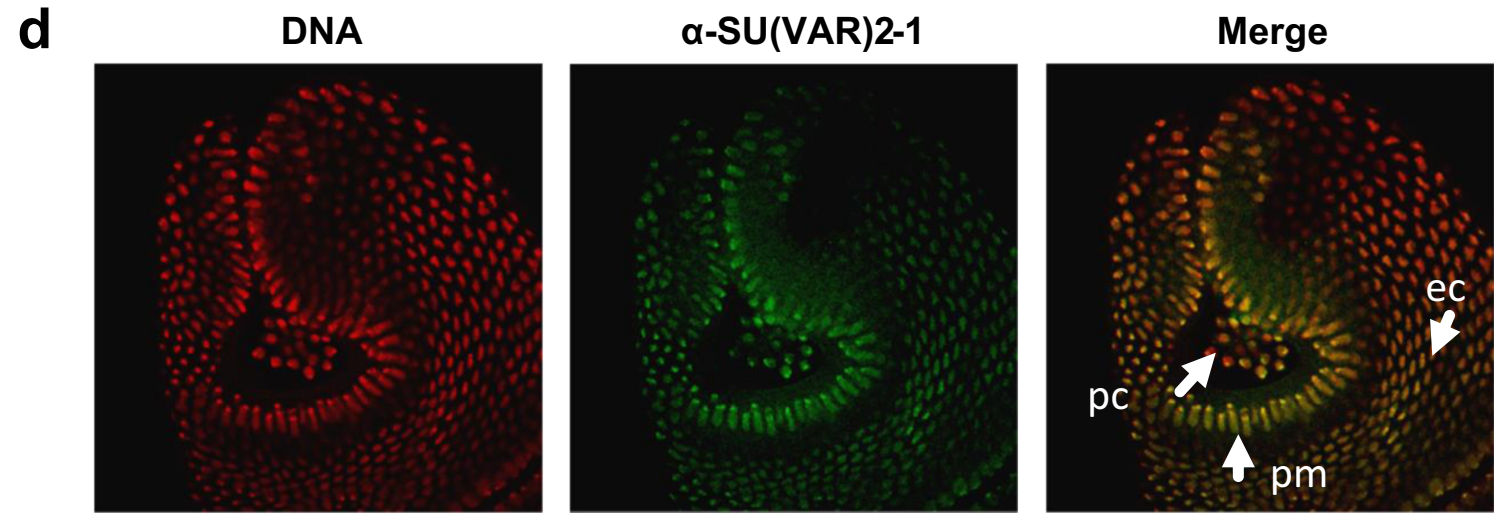

Fig. 3 Apico-basal chromosome orientation and heterochromatin association of SU(VAR)2-1 in blastoderm nuclei. a Fluorescence in situ analysis with DIG-labeled DNA probes for the heterochromatic $359 \mathrm{bp}$ satellite repeat, the sub-telomeric $2 \mathrm{R}$ and $3 \mathrm{R}$ Invader 4 repeats, a painting probe for the distal $\mathrm{X}$ chromosome and for the $\mathrm{R} 1$ retrotransposon repeat distal to the X-chromosomal nucleolus organizer. b Antibody staining for the centromere-specific protein CID, the heterochromatic $\mathrm{H} 3 \mathrm{~K} 9 \mathrm{me} 2$ histone mark, the heterochromatin protein HP1a and SU(VAR)2-1. All the heterochromatic sequences, the heterochromatic histone marks and the HP1a and SU(VAR)2-1 proteins are apically located. $\mathbf{c}$ The euchromatic histone modification marks $\mathrm{H} 3 \mathrm{~K} 9 \mathrm{ac}, \mathrm{H} 3 \mathrm{~K} 4 \mathrm{me} 2, \mathrm{H} 3 \mathrm{~K} 4 \mathrm{me} 3$ and H3K27me3 identify euchromatin extending from heterochromatin toward the basal pole of the nuclei. $\mathbf{d}$ Embryo at early gastrulation showing the posterior midgut rudiment with internalized germ-line cells (glc). In nuclei of primordial cells in posterior midgut (pmg) SU(VAR)2-1 is rather uniformly distributed, although still more abundant at the apical pole of the nucleus. In nuclei of ectodermal cells (ec) SU(VAR)2-1 shows uniform nuclear distribution. DAPI staining of DNA in red, antibody and fluorescence staining in green

Studies to determine the molecular basis for PEVmodifier effects displayed by Jill mutations revealed that double $\mathrm{H} 3 \mathrm{~K} 9 \mathrm{me} 2 \mathrm{~S} 10$ ph indexing of pericentric heterochromatin is essential for white gene silencing in $w^{m 4}$ (Wang et al. 2014). These studies suggested that the histone H3S10-specific kinase JIL1 depends on the 
a

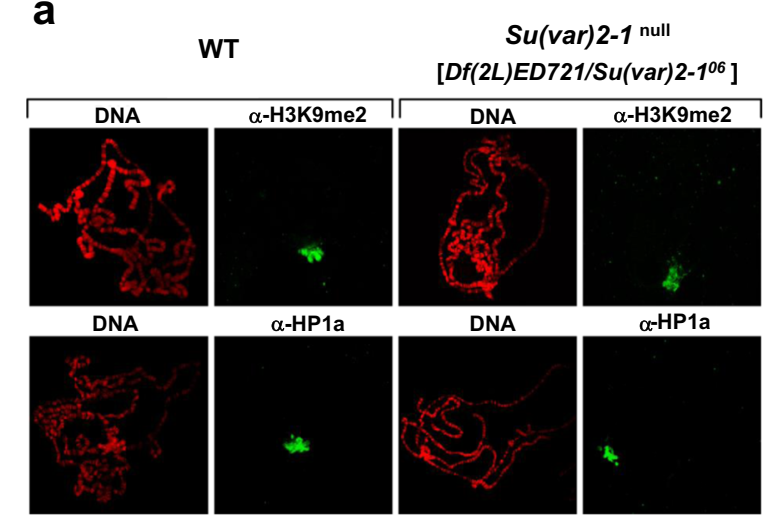

C

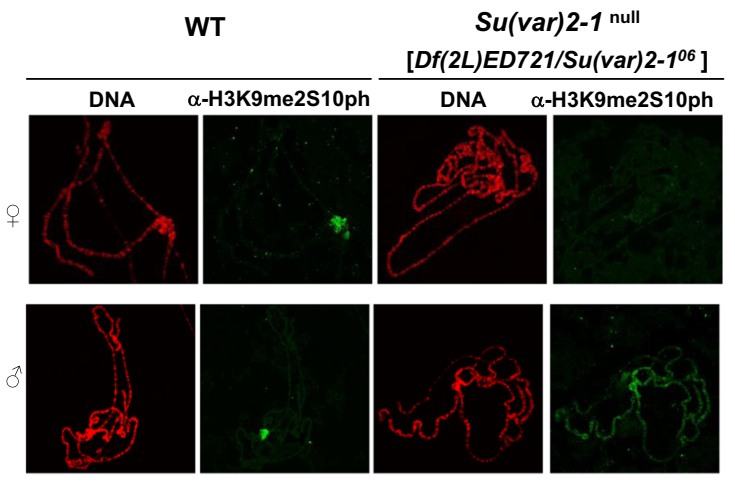

Fig. 4 In Su(var)2-1 null mutants heterochromatic H3K9me2- and HP1abinding are unaffected, whereas $\mathrm{H} 3 \mathrm{~K} 9 \mathrm{me} 2 \mathrm{~S} 10$ pho double indexing is impaired. a Chromocenter staining for $\mathrm{H} 3 \mathrm{~K} 9 \mathrm{me} 2$ and $\mathrm{HP} 1 \mathrm{a}$ in larval salivary gland polytene chromosomes is identical between wild-type and a Su(var)2-1 null $\left\{D f(2 L) E D 721 / S u(v a r) 2-1^{06}\right\}$ genotype. b ChIP analysis of $\mathrm{H} 3 \mathrm{~K} 9 \mathrm{me} 2$ spreading along the white-roughest region juxtaposed in $\operatorname{In}(1) w^{m 4 h}$ to pericentric heterochromatin in adult female heads. No difference between wild-type (white bars) and Su(var)2-1 null flies (gray bars) is found. Error bars indicate standard deviation. c Heterochromatin-specific double-indexing by $\mathrm{H} 3 \mathrm{~K} 9 \mathrm{me} 2 \mathrm{~S} 10$ pho is impaired in $S u$ (var)2-1 null larval salivary gland polytene chromosomes. In females, H3K9me2S10pho is lost, whereas it is ectopically distributed

SU(VAR)3-9 H3K9 KMTase to establish the heterochromatin-specific composite $\mathrm{H} 3 \mathrm{~K} 9 \mathrm{me} 2 \mathrm{~S} 10 \mathrm{ph}$ mark in chromocenters of salivary gland polytene chromosomes (Wang et al. 2014).

In $\mathrm{Su}$ (var)2-1 null mutants, indexing of heterochromatin with the composite $\mathrm{H} 3 \mathrm{~K} 9 \mathrm{me} 2 \mathrm{~S} 10$ ph histone mark was strongly impaired. In salivary gland polytene chromosomes of female larvae H3K9me2S10ph in chromocenter heterochromatin was strongly reduced, whereas in Su(var) 2-1 mutant male larvae significant ectopic distribution of the composite $\mathrm{H} 3 \mathrm{~K} 9 \mathrm{me} 2 \mathrm{~S} 10 \mathrm{ph}$ mark along the chromosomes was observed (Fig. 4c).

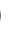

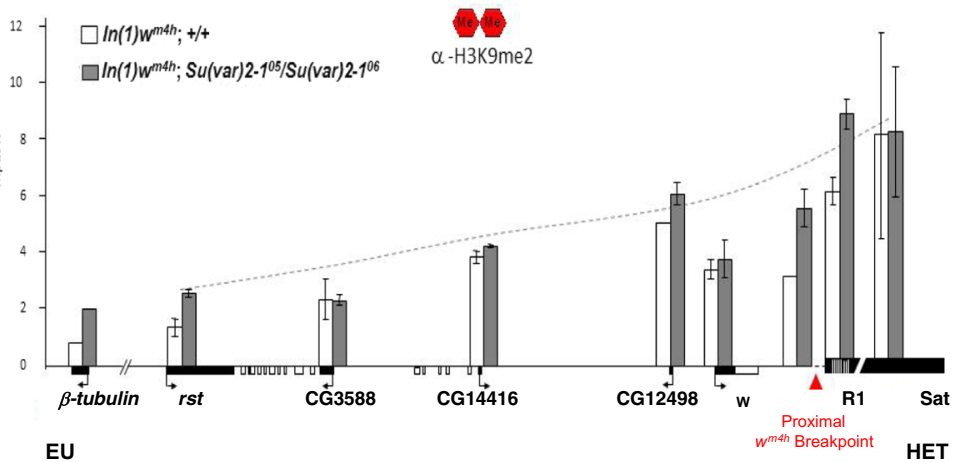

EU 
Next, we tested the levels of H3K9, H3K18, H3K23, H3K27, H4K5, H4K8, H4K12 and H4K16 acetylation on larval salivary gland chromosomes. Immunostaining and Western blot analysis in the Su(var)2-1 null mutant showed a strong global increase in H3K9ac, H3K18ac, H3K27ac, H4K8ac and H4K16ac (Fig. 5a-c). Remarkably, larvae of the $\mathrm{Su}$ (var)2-1 null mutant showed strong staining of chromocenter heterochromatin for H3K9ac, H3K18ac, H3K27ac, H4K8ac and H4K16ac (Fig. 5a, b). This suggests impaired indexing of heterochromatin with the silencing-associated H3K9me2 (Fig. 4a), the active H3K9ac and H3K27ac marks together with high levels of H4K16ac (Fig. 5a, b, Fig. S5a).

In addition, a significant increase in $\mathrm{H} 4 \mathrm{~K} 16 \mathrm{ac}$ was found along autosomes in both females and males. Ectopic distribution and elevated levels of H4K16ac raises the question of whether a possible effect of the $\mathrm{Su}$ (var)2-1 mutation on $\mathrm{X}$ chromosome dosage-compensation occurs. We therefore

a
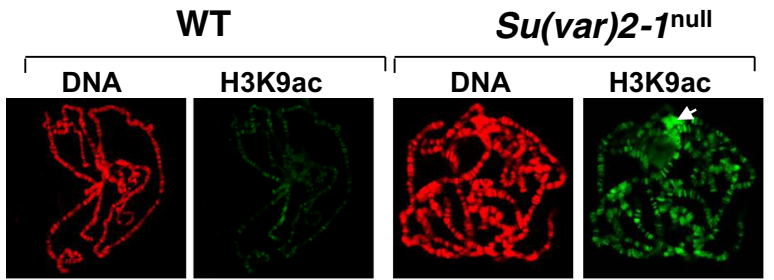

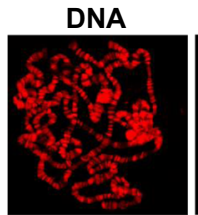

DNA

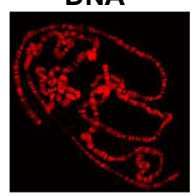

DNA

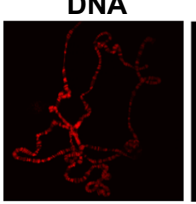

H3K18ac

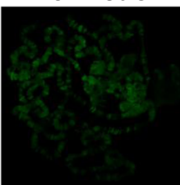

H3K27ac

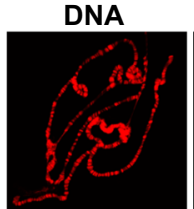

H3K18ac

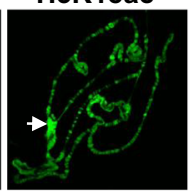

DNA

H3K27ac

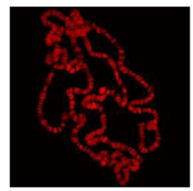

DNA

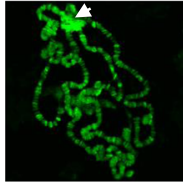

H4K8ac
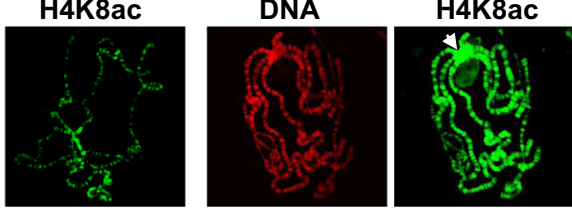

C

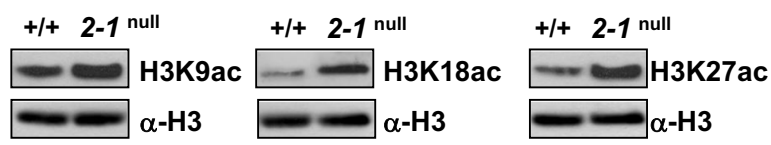

Fig. 5 In $S u$ (var)2-1 null polytene chromosomes the levels of H3K9ac, H3K18ac, H3K27ac, H4K8ac and H4K16ac are strongly increased. a Antibody staining of Su(var)2-1 ${ }^{06} / D f(2 L) S u(v a r) 2-1^{d s}\{S u(v a r) 2-1$ null $\}$ larvae shows, when compared with wild-type, significantly higher levels of H3K9ac, H3K18ac, H3K27ac, H4K8ac and H4K16ac along the euchromatic chromosome arms and in chromocenter heterochromatin. White arrows point to chromocenters. b The increase in H4K16 studied chromosomal distribution of the MOF and MSL-1 components of the dosage-compensation complex DCC (Ferrari et al. 2014). Immunostaining with a MOF-specific antibody, when compared with wild-type, revealed no difference in chromosomal association of MOF in female and male larvae of the $S u$ (var) 2-1 mutant. Specific association of MSL1 with the male X-chromosome was also unaffected (Fig. S5a). H4K5ac, which is normally found in chromocenter heterochromatin, was not significantly changed in male Su(var)2-1-null larvae; however, in females, high H4K5acstaining was only found in the chromocenter but appeared to be reduced along euchromatin (Fig. S5b).

The effects of Su(var)2-1 overexpression on histone acetylation levels was studied for $\mathrm{H} 3 \mathrm{~K} 9 \mathrm{ac}$ and $\mathrm{H} 3 \mathrm{~K} 27 \mathrm{ac}$ in homozygous Su(var)2-1 $1^{+} P\{U A S T$-attB Strep-Su(var)2-1-V5$3 x F L A G\}$ larvae carrying altogether four $S u(v a r) 2-1^{+}$gene copies. Compared with wild-type larvae, both H3K9ac and

b

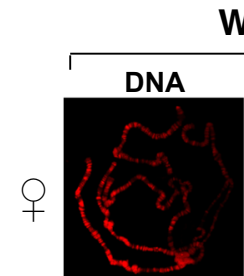
VT Su(var)2-1 null
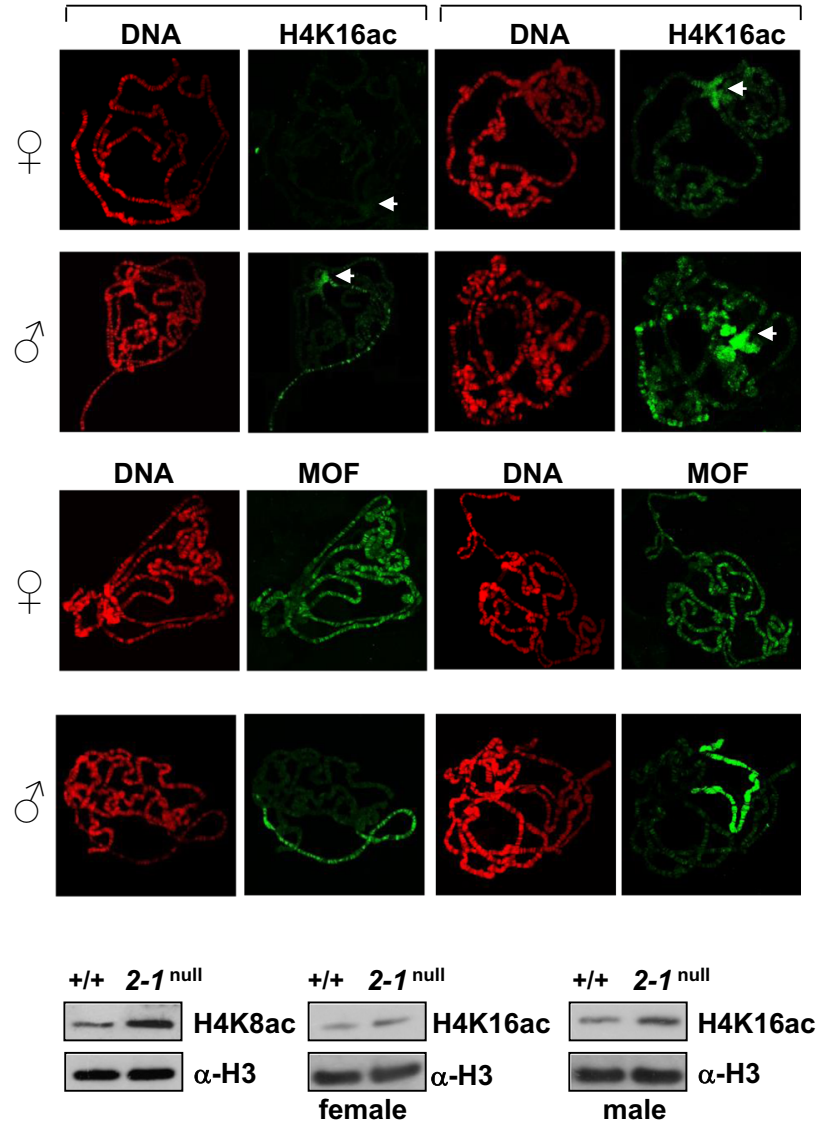

acetylation is most prominent in chromocenter heterochromatin. In males the X-chromosome also shows increased staining for H4K16ac and MOF although no obvious effects on dosage compensation are observed. Compared with wild-type the male X-chromosome frequently appears to be more condensed in $S u(v a r) 2-1$ null mutant larvae. c The global increase in all the studied histone acetylation marks is supported by Western blot analysis 
H3K27ac were significantly reduced (Fig. S5c). In addition, $w^{m 4 h}$ flies with four $\mathrm{Su}$ (var) $2-1^{+}$copies displayed a strong enhancement of white variegation in the eye (Fig. S5d). The data show that the dosage-dependent effect of Su(var)2-1 on histone-acetylation levels was negatively correlated with its effect on heterochromatic gene silencing of the white gene in the $w^{m 4 h}$ PEV rearrangement.

\section{SU(VAR)2-1 recruits the dRPD3 histone deacetylase to chromatin}

Due to the prominent role of the histone deacetylase dRPD3 (dHDAC1) in the control of gene expression during developmental processes (Chen et al. 1999; Miotto et al. 2006) through histone $\mathrm{H} 3 \mathrm{~K} 9$ and $\mathrm{H} 3 \mathrm{~K} 27$ deacetylation (Tie et al. 2009), it was important to study the nuclear distribution of RPD3 on larval salivary gland polytene chromosomes in Su(var)2-1-null mutant larvae. We identified a strong reduction in RPD3 chromosome-association (Fig. 6a), suggesting a pivotal role for SU(VAR)2-1 in RPD3 recruitment to chromosomes. Despite a reduced global level of the dRPD3 protein, the expression of the $d R p d 3$ gene was not affected by the Su(var)2-1-null genotype (Fig. 6b). The SU(VAR2-1-EGFP fusion protein was isolated using a GFP-Trap from larval salivary glands containing a $P\{U A S-S U(V A R) 2-1-E G F P\}$ transgene expressed by the actin-GAL4 driver, and we tested by coimmunoprecipitation for its possible association with RPD3. The results showed significant association of RPD3 to SU(VAR)2-1 (Fig. 6c). These data suggest that the SU(VAR)2-1 protein is required for normal chromosomal association of RPD3.

\section{SU(VAR)2-1 controls chromatin restructuring before mid-blastula transition (pre-MBT)}

In wild-type embryos abundant H3K9ac, H3K27ac and H4K16ac histone indexing was found up to nuclear cycle 12. Subsequent strong deacetylation of chromatin occurred between nuclear cycle 12 and 13 at pre-MBT in wild-type embryos (Fig. 7a). The SU(VAR)2-1/RPD3 interaction, which was demonstrated for salivary gland chromosomes, was also observed after co-immunoprecipitation experiments in early embryos (Fig. S6). In embryos produced by females that are homozygous for the hypomorphic $S u(v a r) 2-1^{10}$ allele, the abundant histone acetylation at pre-MBT was not removed by deacetylation (Fig. 7a). As a consequence, R1 a
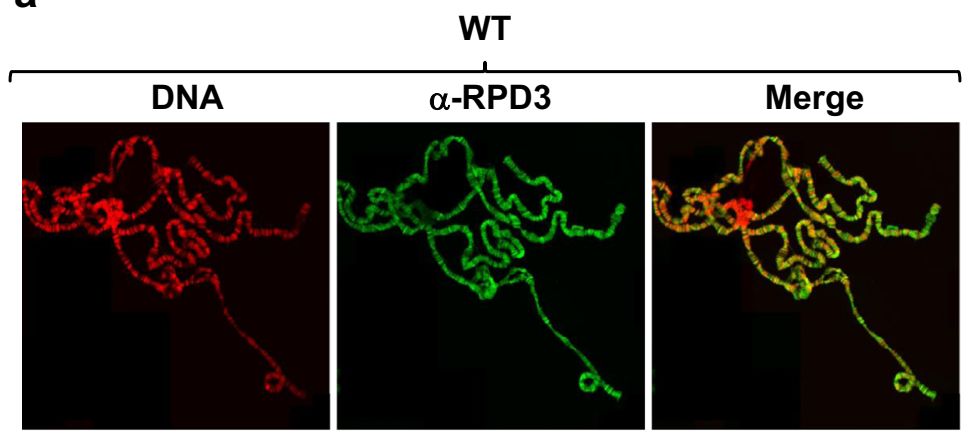

Su(var)2-1 null

[Df(2L)ED721/Su(var)2-106]
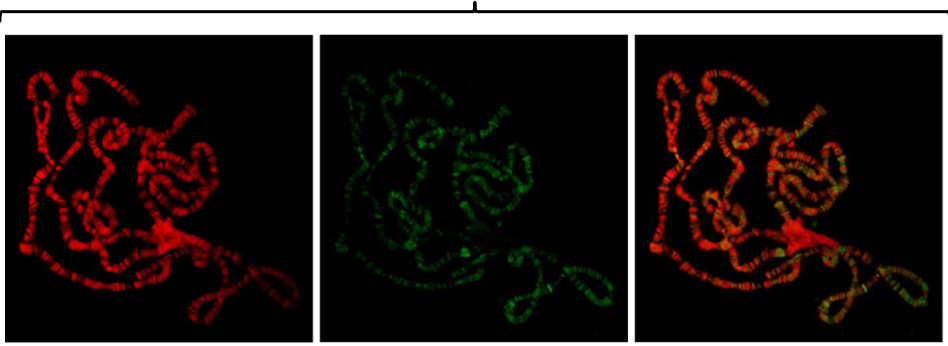

b

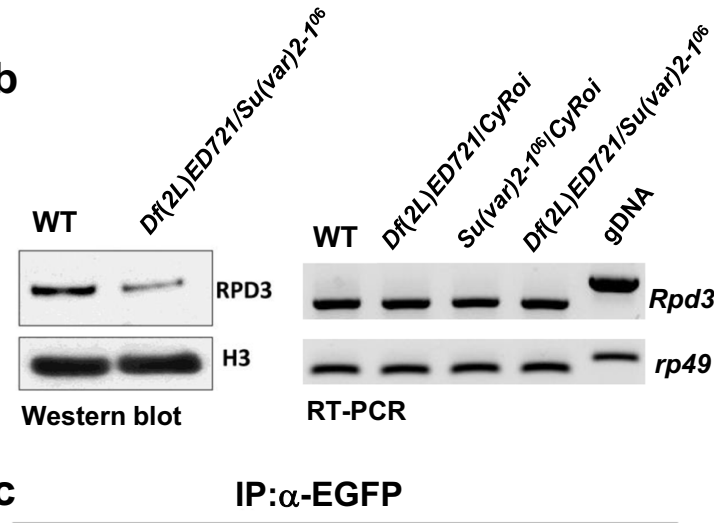

C

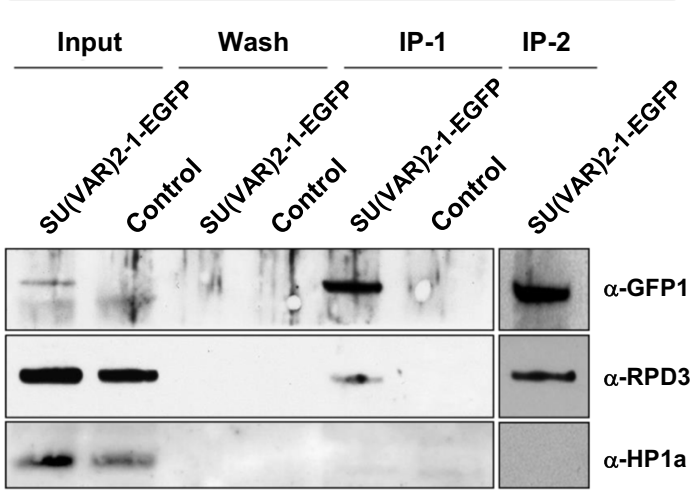

Fig. 6 SU(VAR)2-1 recruits the histone deacetylase RPD3 to numerous chromosomal sites. a Immunostaining of $\mathrm{Su}$ (var)2-1-null larval salivary glands with a RPD3-specific polyclonal antibody shows significant reduction of RPD3 chromosome association. b Western analysis of Su(var)2-1-null [Df(2L)ED721/Su(var)2-1 $\left.{ }^{06}\right]$ suggests global reduction of RPD3 although expression of the Rpd3 gene is unchanged. c Co- immunoprecipitation of SU(VAR)2-1 and RPD3 was studied in extracts derived from transgenic larval salivary glands producing a SU(VAR)2-1EGFP fusion protein purified with GFP-Trap beads. Precipitated proteins were studied by Western blot analysis using EGFP and RPD3 specific polyclonal antibodies. In Fig. 5c, the blots of two independent immunoprecipitations are shown (indicated with IP1 and IP2) 

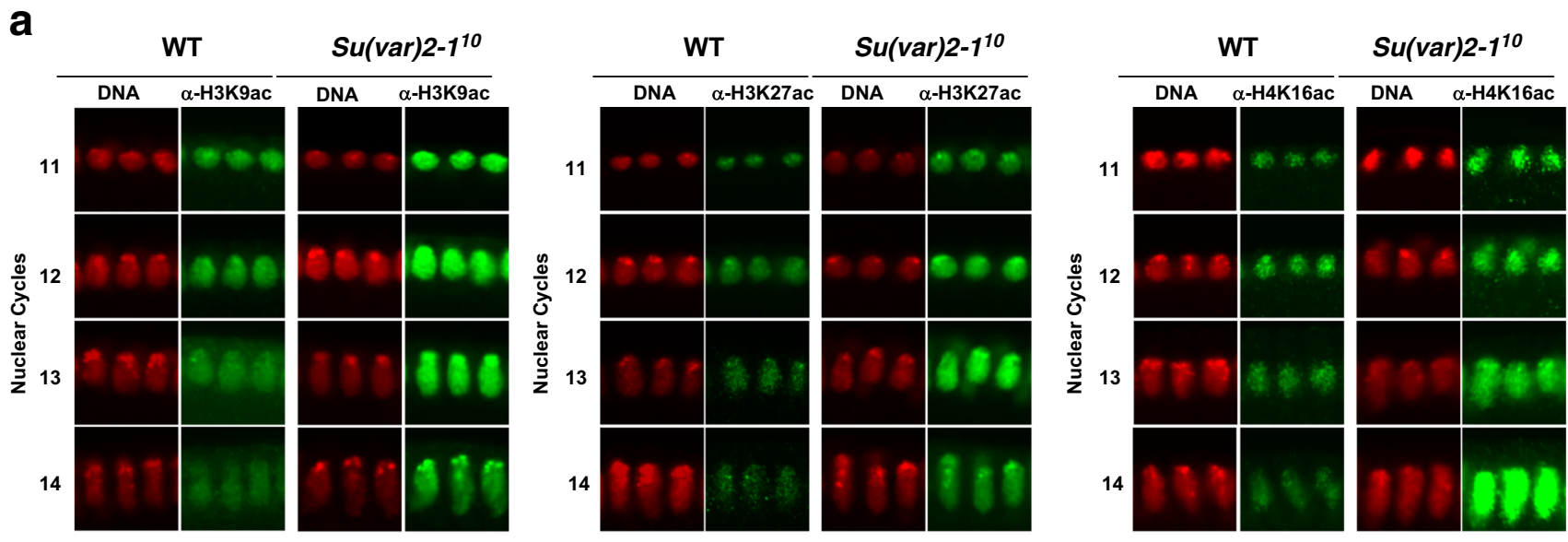

b

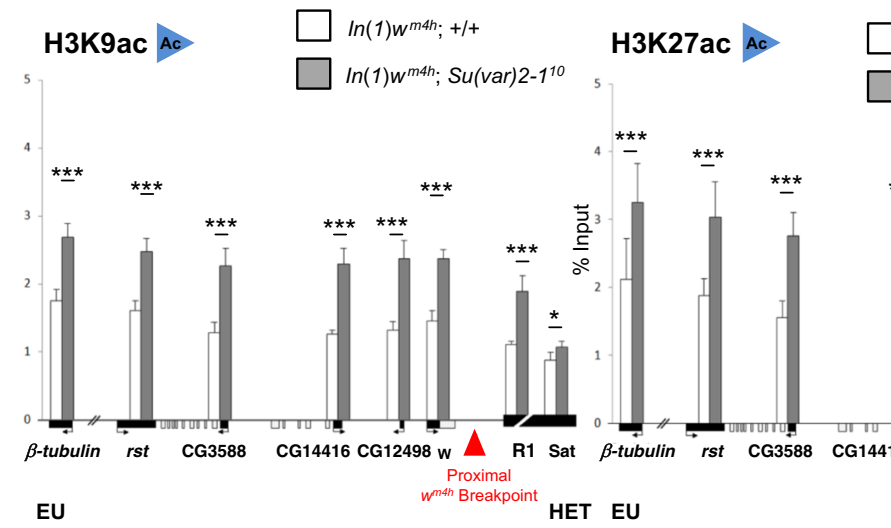

Fig. 7 SU(VAR)2-1-controlled global histone deacetylation at pre-MBT is essential for normal heterochromatin formation. a Immunocytology of blastoderm nuclei at cycles 11, 12, 13 and 14 for H3K9ac, H3K27ac and H4K16ac from embryos produced by wild-type and $\mathrm{Su}$ (var)2-1 ${ }^{10}$ homozygous females. In wild-type, the studied acetylation marks are prominent histone modifications in syncytial nuclei and in blastoderm at cycles 11 and 12 but are strongly reduced at cycles 13 and 14 when establishment of heterochromatin and euchromatin is initiated. Contrary to Su(var)2-1-null females, which are agametic homozygous, $S u(v a r) 2-1^{10}$ females are fertile. Requirement of SU(VAR)2-1 for histone deacetylation at pre-MBT is reflected by strong elevation of all studied acetylation marks in blastoderm nuclei of $\mathrm{Su}$ (var) 2-1 $1^{10}$ mutant embryos. b ChIP analysis of H3K9ac, $\mathrm{H} 3 \mathrm{~K} 27 \mathrm{ac}$ and $\mathrm{H} 4 \mathrm{~K} 16 \mathrm{ac}$ along the white-roughest region juxtaposed in

heterochromatic sequences at the heterochromatic breakpoint of $w^{m 4 h}$ showed elevated levels of H3K9ac and H3K27ac, as is observed for euchromatic $\mathrm{X}$ chromosomal sequences. At the heterochromatic $359 \mathrm{bp}$ satellite sequences an increase in H3K27ac was found (Fig. 7b). Impairment of pre-MBT histone deacetylation in $\mathrm{Su}$ (var) $2-1^{10}$ mutant embryos resulted in ambivalent histone modification at prospective heterochromatin, which was maintained and even intensified during consecutive development, as shown for adult heads (Fig. 4) and heterochromatic chromocenters at larval polytene chromosomes (Fig. 5). Together, these data suggest an essential role for SU(VAR)2-1 in induction of heterochromatin at pre-MBT.

\section{The SU(VAR)2-1 function at pre-MBT is maternally controlled}

The maternal function of SU(VAR)2-1 in chromatin reorganization at pre-MBT was resolved by reciprocal crosses using a $P\{U A S T-a t t B$ Strep-Su(var)2-1-V5-3xFLAG $\}$ transgene. The transgene expresses a SU(VAR)2-1 fusion protein with an Nterminal STREP and C-terminal V5-3xFLAG tag under the control of the endogenous $\mathrm{Su}(\mathrm{var}) 2-1$ promoter. This transgene effectively rescued all Su(var)2-1 mutant phenotypes (Fig. 1d and Fig. S4). Using the SU(VAR)2-1 fusion protein, it was possible to monitor production of the SU(VAR)2-1 
protein originating from the paternally inherited gene during embryonic development. The protein originating from the paternal allele was first detected in embryos at the beginning of gastrulation (Fig. S7), suggesting that all Su(var)2-1 mutant phenotypes observed during early embryonic development depend on maternal contribution of SU(VAR)2-1. This can be concluded because a zygotic contribution of the paternal allele could only be detected at the beginning of gastrulation.

\section{Discussion}

\section{Developmental regulation of step-wise heterochromatin establishment in Drosophila}

$\mathrm{Su}$ (var) mutations of gene silencing in position-effect variegation (PEV) in Drosophila have been instrumental in the identification and functional analysis of chromatin components controlling establishment of heterochromatin. Histone H3K9 di- and tri-methylation is central to heterochromatin formation, which is catalyzed by the histone methyltransferases SU(VAR)3-9 in pericentric heterochromatin (Schotta et al. 2002) and dSETDB1 in the 4th chromosome, at telomeres, repeats and retrotransposons (Seum et al. 2007; Tzeng et al. 2007; Phalke et al. 2009). The H3K9me2 and H3K9me3 marks constitute a binding surface for the HP1a chromo domain (Fischle et al. 2003), which recruits a protein complex containing other $\mathrm{Su}$ (var) factors like dADD1 and SU(VAR)2HP2 (Alekseyenko et al. 2014).

All these factors represent PEV Su(var) genes, which are essential in establishing a heterochromatic chromatin state. However, the heterochromatin-establishing SU(VAR) factors depend on the function of earlier-acting, heterochromatininitiating SU(VAR) factors, which are required to generate pre-conditions for heterochromatin formation. dLSD1 \{SU(VAR)3-3\} was the first Su(var) gene to be identified that encodes a heterochromatin-initiating SU(VAR) factor, and which secures H3K9 methylation by the KMTase SU(VAR)3-9 (Rudolph et al. 2007). The dLSD1 histone demethylase binds preferentially to prospective heterochromatin in blastoderm nuclei and protects heterochromatic sequences against deposition of the active $\mathrm{H} 3 \mathrm{~K} 4 \mathrm{me} 1 / \mathrm{me} 2$ methylation marks in early MBT. SU(VAR)2-1 exerts a comparable function by controlling removal of abundant histone acetylation from prospective pericentric heterochromatin at preMBT through recruitment of the histone deacetylase RPD3.

More complex heterochromatin-initiating mechanisms have been revealed by new high-resolution techniques. TALE-light imaging showed H3K9me2/me3-independent HP1a recruitment to individual satellite sequences and the JabbaTrap technique revealed an important maternal function of the SETDB1 KMTase in heterochromatin initiation at early MBT (Yuan and O'Farrell 2016; Seller et al. 2019).
In Schizosaccharomyces pombe, the multi-enzyme complex SHREC containing the histone deacetylase $\mathrm{Clr} 3$ is essential for heterochromatin initiation (Sugiyama et al. 2007). In Drosophila, recruitment of RPD3 to prospective heterochromatin depends on SU(VAR)2-1, whereas in $S$. pombe recruitment of the SHREC complex is either Swi6/HP1-dependent or depends on sequence-specific binding proteins such as Atf1/Pcr1 (Yamada et al. 2005; Sugiyama et al. 2007). Establishment of facultative heterochromatin domains in S. pombe also depends on HDAC-dependent histone deacetylation (Watts et al. 2018). In Arabidopsis thaliana, initiation of heterochromatic silencing requires the histone deacetylase HDA6 (Aufsatz et al. 2002). Taken together, initiation of heterochromatic silencing by histone deacetylation may be a general and evolutionarily conserved mechanism in eukaryotes, whereas, due to the more complex developmental programs of higher eukaryotes, recruitment processes appear to differ significantly.

A third group of heterochromatin-maintaining SU(VAR) factors are also predicted and might protect the heterochromatic state for stable transmission across mitotic cell division. Although some of the heterochromatin-maintaining SU(VAR) factors are currently not fully defined, they are likely to comprise chromatin remodelers and/or histone-exchange factors. This is supported by the strong recessive suppressor effects of acfl mutations on $w^{m 4} \mathrm{PEV}$, a main component of the Drosophila ACF/CHRAC nucleosome remodeling complex (Fyodorov et al. 2004). In heterochromatin, nucleosomes are regularly spaced and their turnover is inhibited by the histone deacetylase Clr3, e.g. in fission yeast (Aygün et al. 2013). SU(VAR)2-1 in Drosophila might also have a role as a maintenance factor by recruiting RPD3 to many band regions, which are suggested to contain inactive genes.

\section{SU(VAR)2-1 and chromatin reorganization before mid-blastula transition (pre-MBT)}

Syncytial nuclei in Drosophila divide by oscillating between DNA synthesis and mitosis without gap phases. Cell cycle control first occurs at cycle 13 by extension of the S-phase, when a G2-phase is introduced. Prolongation of the S-phase at cycle 13 is correlated with delayed replication of heterochromatic regions (McCleland et al. 2009; Shermoen and McCleland 2014; Yuan et al. 2014). The G1-phase is not introduced until cycle 17. Main zygotic genome activation occurs at mitotic cycle 14, which coincides with enrichment of active epigenetic marks, transcription and chromatinremodeling factors (Darbo et al. 2013). Changes in cell cycle and zygotic genome activation represent the main wellstudied events that define the period of MBT during early embryonic development in Drosophila (Yuan et al. 2016).

However, global changes in chromatin organization at preMBT and the control of such processes had not yet been studied. Our data show that chromatin organization in the rapidly 


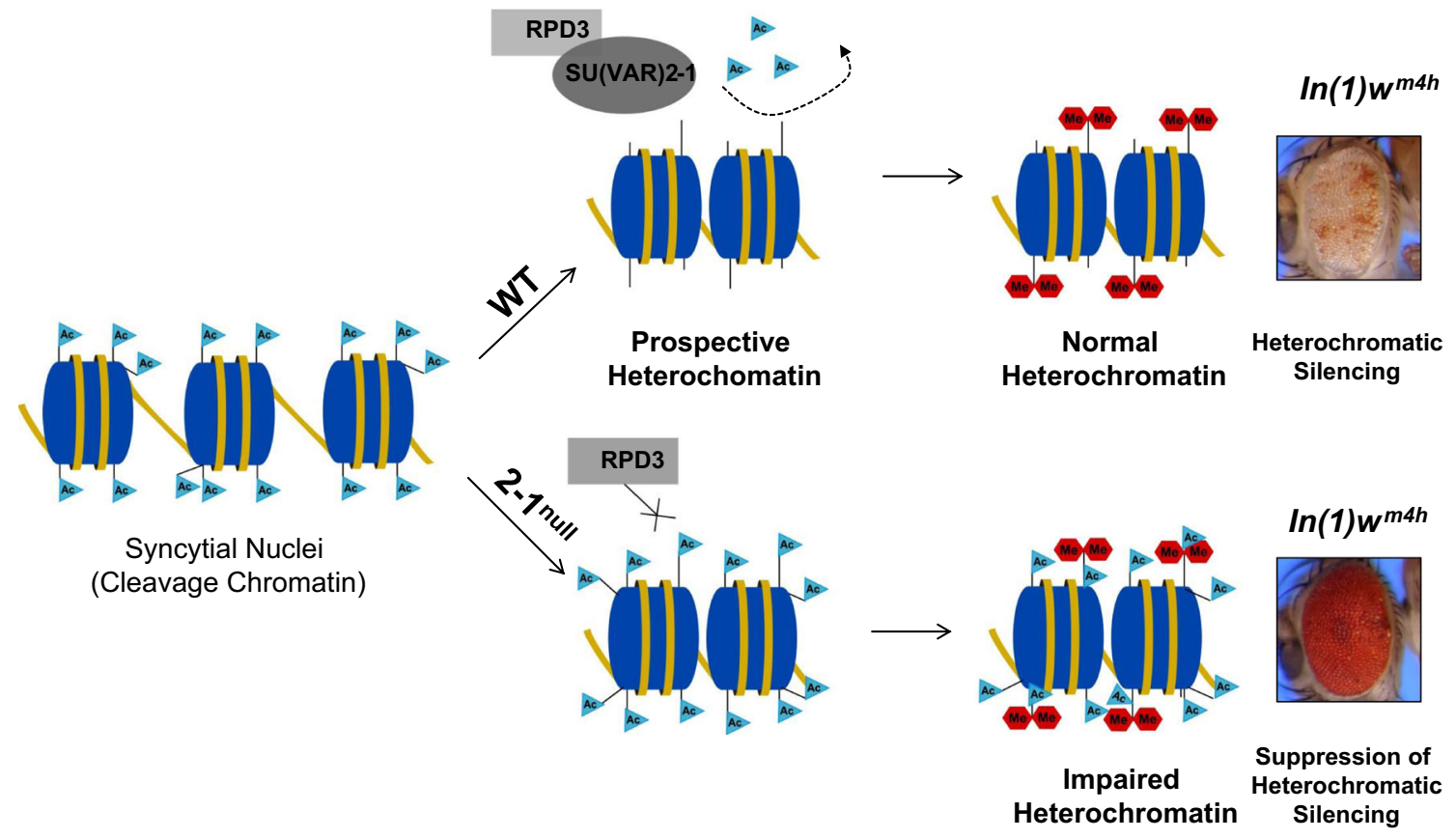

Fig. 8 Heterochromatin formation depends on global histone deacetylation at the transition of naive syncytial (cleavage) chromatin to somatic blastoderm chromatin. SU(VAR)2-1 is an abundant chromatin protein of syncytial nuclei and in early blastoderm nuclei. At cycles 1314 in blastoderm nuclei, SU(VAR)2-1 accumulates at heterochromatic regions at the apical pole. During transition of naive cleavage chromatin into somatic and germ-line chromatin, it is essential for global histone

dividing syncytial nuclei is unique and differs significantly in the abundance of histone-indexing modifications. Abundant histone acetylation is found in the syncytial cleavage nuclei, whereas many other histone modification marks are underrepresented or completely missing, including $\mathrm{H} 3 \mathrm{~K} 4, \mathrm{H} 3 \mathrm{~K} 9$, H3K27 methylation or H3K36me3 (Rudolph et al. 2007). SU(VAR)2-1 controls global histone deacetylation at preMBT, in particular for H3K9ac, H3K27ac and H4K16ac. This function of SU(VAR)2-1, by recruiting the RPD3 histone deacetylase, appears to be essential for transition of a cleavage chromatin state into an early blastoderm chromatin state, which is competent for differentiation of euchromatin and heterochromatin. Binding of SU(VAR)2-1 to heterochromatic sequences in blastoderm nuclei removes active histone acetylation marks from prospective heterochromatin by recruiting RPD3. Retaining high $\mathrm{H} 3 \mathrm{~K} 9$ and $\mathrm{H} 3 \mathrm{~K} 27$ acetylation levels in prospective heterochromatin in the blastoderm at pre-MBT causes impaired heterochromatin indexing, which later is maintained and even elevated during subsequent development (Fig. 8).

Acknowledgements The authors are grateful to the former members of the Halle group Janina Bär, Olaf Nickel, and Martin Schicht for their support. We acknowledge G. Sawers, V. Pirrotta, and J. Szabad for their helpful comments on the manuscript. We thank the Bloomington Drosophila Stock Center (NIH P40OD018537) for Drosophila strains.

\section{Blastoderm Nuclei}

deacetylation to occur before mid-blastula transition. SU(VAR)2-1 is required for complete removal of, and protection against, histone acetylation at heterochromatic sequences. SU(VAR)2-1 physically interacts with RPD3 and is required for its normal chromatin association suggesting that RPD3 is the main deacetylase controlling early embryonic chromatin transition through $\mathrm{H} 3 \mathrm{~K} 9 \mathrm{ac}, \mathrm{H} 3 \mathrm{~K} 27 \mathrm{ac}$ and $\mathrm{H} 4 \mathrm{~K} 16 \mathrm{ac}$ deacetylation

Author contributions M.W., T.J. and G.R. designed experiments. M.W., S.S., V.K., S.L., J.K. and G.R. performed experiments. M.W., S.S., V.K., S.L, J.K. and G.R. performed data analysis. G.R., M.W. and T.J., wrote the manuscript. All authors approved the submission.

Funding information Open Access funding provided by Projekt DEAL. We further thank Maria Kube, Ramona Abe and Kathrin Kittlaus for experimental support. Research in the laboratory of G.R. was supported by Deutsche Forschungsgemeinschaft (DFG). The Max-Planck Society and DFG supported studies conducted in the T.J. laboratory.

\section{Compliance with ethical standard}

Conflict of interest The authors declare that they have no conflict of interest.

Open Access This article is licensed under a Creative Commons Attribution 4.0 International License, which permits use, sharing, adaptation, distribution and reproduction in any medium or format, as long as you give appropriate credit to the original author(s) and the source, provide a link to the Creative Commons licence, and indicate if changes were made. The images or other third party material in this article are included in the article's Creative Commons licence, unless indicated otherwise in a credit line to the material. If material is not included in the article's Creative Commons licence and your intended use is not permitted by statutory regulation or exceeds the permitted use, you will need to obtain permission directly from the copyright holder. To view a copy of this licence, visit http://creativecommons.org/licenses/by/4.0/. 


\section{References}

Alekseyenko AA, Gorchakov AA, Zee BM, Fuchs SM, Kharchenko PV, Kuroda MI (2014) Heterochromatin-associated interactions of Drosophila HP1a with dADD1, HIPP1, and repetitive RNAs. Genes Dev 28:1445-1460

Allshire RC, Madhani HD (2017) Ten principles of heterochromatin formation and function. Nat Rev Mol Cell Biol 19:229-244

Aufsatz W, Mette MF, van der Winden J, Matzke M, Matzke AJ (2002) HDA6, a putative histone deacetylase needed to enhance DNA methylation induced by double-stranded RNA. EMBO J 21:68326841

Aygün O, Mehta S, Grewal SIS (2013) HDAC mediated suppression of histone turnover promotes epigenetic stability of heterochromatin. Nat Struct Mol Biol 20:547-554

Baksa K, Morawietz H, Dombradi V, Axton M, Taubert H, Szabo G, Török I, Gyurkovics H, Szöör B, Gloover D et al (1993) Mutations in the phosphatase 1 gene at $87 \mathrm{~B}$ can differentially affect suppression of position-effect variegation and mitosis in Drosophila melanogaster. Genetics 135:117-125

Bischof J, Maeda RK, Hediger M, Basler K (2007) An optimized transgenesis system for Drosophila using germ-line-specific phiC31 integrases. Proc Natl Acad Sci U S A 104:3312-3317

Bulut-Karslioglu A, Perrera V, Scaranaro M, de la Rosa-Velazquez IA, van de Nobelen S, Shukeir N, Popow J, Gerle B, Opravil S, Pagani $\mathrm{M}$ et al (2013) A transcription factor-based mechanism for mouse heterochromatin formation. Nat Struct Mol Biol 19:1023-1030

Chen G, Fernandez J, Mische S, Courey AJ (1999) A functional interaction between the histone deacetylase $\mathrm{Rpd} 3$ and the corepressor Groucho in Drosophila development. Genes Dev 13:2218-2230

Darbo E, Herrmann C, Lecuit T, Thieffry D, Helden J (2013) Transcriptional and epigenetic signatures of zygotic genome activation during early Drosophila embryogenesis. BMC Genomics 14: 226-248

Dellino GI, Schwartz YB, Farkas G, McCabe D, Elgin SC, Pirrotta V (2004) Polycomb silencing blocks transcription initiation. Mol Cell 13:887-893

DeRubertis F, Kadosh D, Henchoz S, Pauli D, Reuter G, Struhl K, Spierer P (1996) The histone deacetylase RPD3 counteracts genomic silencing in Drosophila and yeast. Nature 384:589-591

Di Stefano L, Ji JY, Moon NS, Herr A, Dyson N (2007) Mutation of Drosophila Lsd1 disrupts H3-K4 methylation, resulting in tissuespecific defects during development. Curr Biol 17:808-812

Dimitri P, Pisano C (1989) Position effect variegation in Drosophila melanogaster: relationship between suppression effect and the amount of Y chromosome. Genetics 122:793-800

Domcke S, Bardet AF, Ginno PA, Hartl D, Burger L, Schübeler D (2015) Competition between DNA methylation and transcription factors determines binding of NRF1. Nature 528:575-579

Dorn R, Heymann S, Lindigkeit R, Reuter G (1986) Suppressor mutation of position-effect variegation affecting chromatin properties. Chromosoma 93:398-403

Dorn R, Krauss V, Reuter G, Saumweber H (1993a) The enhancer of position-effect variegation of Drosophila, E(var)3-93D, codes for a chromatin protein containing a conserved domain to several transcription regulators. Proc Natl Acad Sci U S A 90:11376-11380

Dorn R, Szidonya J, Korge G, Sehnert M, Taubert H, Archoukieh I, Tschiersch B, Morawietz H, Wustmann G, Hoffmann G et al (1993b) P transposon-induced dominant enhancer mutations of position-effect variegation in Drosophila melanogaster. Genetics 133:279-290

Edgar RC (2004) MUSCLE: multiple sequence alignment with high accuracy and high throughput. Nucl Acids Res 32:1792-1797

Eissenberg JC, Morris GD, Reuter G, Hartnett T (1992) The heterochromatin-associated protein HP-1 is an essential protein in
Drosophila with dosage-dependent effects on position-effect variegation. Genetics 131:345-352

Ejsmont RK, Sarov M, Winkler S, Lipinski KA, Tomancak P (2009) A toolkit for high-throughput, cross-species gene engineering in Drosophila. Nature Methods 6:435-437

Elgin SCR, Reuter G (2013) Position-effect variegation, heterochromatin formation, and gene silencing in Drosophila. Cold Spring Harb Perspect Biol 5:a017780. https://doi.org/10.1101/cshperspect. a017780

Fanti L, Berloco M, Pimpinelli S (1994) Carnitine suppression of position-effect variegation in Drosophila melanogaster. Mol Gen Genet 244:588-595

Farkas G, Gausz J, Galloni M, Reuter G, Gyurkovics H, Karch F (1994) The Trithorax-like gene encodes the Drosophila GAGA factor. Nature 371:806-808

Ferrari F, Alekseyenko AA, Park PJ, Kuroda MI (2014) Transcriptional control of a whole chromosome: emerging models for dosage compensation. Nat Struct Mol Biol 21:118-125

Fischle W, Wang Y, Jacobs SA, Kim Y, Allis CD, Khorasanizadeh S (2003) Molecular basis for the discrimination of repressive methyllysine marks in histone H3 by Polycomb and HP1 chromodomains. Genes Dev 17:1870-1881

Fodor DB, Shukeir N, Reuter G, Jenuwein T (2010) Mammalian Su(var) genes in chromatin control. Ann Rev Cell Dev Biol 26:471-501

Foe VE, Odell GM, Edgar BA (1993) Mitosis and morphogenesis in the Drosophila embryo: point and counterpoint. In the development of Drosophila melanogaster. In: Bate M, Martinez-Arias A (eds), vol 1. Cold Spring Harbor Laboratory Press, Cold Spring Harbor, pp 149-300

Fuchs J, Kuhfittig S, Reuter G, Schubert I (1998) Chromosome painting in Drosophila. Chromosom Res 6:335-336

Fyodorov DV, Blower MD, Karpen GH, Kadonaga JT (2004) Acf1 confers unique activities to $\mathrm{ACF} / \mathrm{CHRAC}$ and promotes the formation rather than disruption of chromatin in vivo. Genes Dev 18:170-183

Girton JR, Johansen KM (2008) Chromatin structure and regulation of gene expression: the lessons of PEV in Drosophila. Adv Genet 61: $1-43$

Gratz SJ, Cummings AM, Nguyen JN, Hamm DC, Donohue LK, Harrison MM, Wildonger J, O'Connor-Giles KM (2013) Genome engineering of Drosophila with the CRISPR RNA-guided Cas9 nuclease. Genetics 194:1029-1035

Gratz SJ, Ukken FP, Rubinstein CD, Thiede G, Donohue LK, Cummings AM, O'Connor-Giles KM (2014) Highly specific and efficient CRISPR/Cas9-catalyzed homology-directed repair in Drosophila. Genetics 196:961-971

Grewal SIS, Jia S (2007) Heterochromatin revisited. Nat Rev Genet 8:3546

Janssen A, Colmenares SU, Karpen GH (2018) Heterochromatin: Guardian of the genome. Annu Rev Cell Dev Biol 6:265-288

Karimi MM, Goyal P, Maksakova IA, Bilenky M, Leung D, Tang JX, Shinkai Y, Mager DL, Jones S, Hirst M, Lorincz MC (2011) DNA methylation and SETDB1/H3K9me3 regulate predominantly distinct sets of genes, retroelements, and chimeric transcripts in mESCs. Cell Stem Cell 8:676-687

Lachner M, O'Carroll D, Rea S, Mechtler K, Jenuwein T (2001) Methylation of histone H3 lysine 9 creates a binding site for HP1 proteins. Nature 410:116-120

Lloret-Llinares M, Carre C, Vaquero A, deOlano N, Azorin F (2008) Characterization of Drosophila melanogaster JmjC $+\mathrm{N}$ histone demethylases. Nucl Acids Res 36:2852-2863

Loubiere V, Delest A, Schuettengruber B, Martinez A, Cavalli G (2017) Chromatin Immunoprecipitation experiments from whole Drosophila embryos or larval Imaginal Discs. Bio Protoc 7:e2327. https://doi.org/10.21769/BioProtoc.2327

Lu X, Sachs F, Ramsay L, Jacques PE, Goke J, Bourque G, Ng HH (2014) The retrovirus HERVH is a long noncoding RNA required 
for human embryonic stem cell identity. Nat Struct Mol Biol 21: 423-425

Maddison WP, Maddison DR (2018) Mesquite: a modular system for evolutionary analysis. Version $3.51 \mathrm{http} / / /$ www.mesquiteproject.org

McCleland ML, Shermoen AW, O'Farrell PH (2009) DNA replication times the cell cycle and contributes to the mid-blastula transition in Drosophila embryos. J Cell Biol 187:7-14

Millanes-Romero A, Herranz N, Perrera V, Iturbide A, Loubat-Casanovas J, Gil J, Jenuwein T, García de Herreros A, Peiró S (2013) Regulation of heterochromatin transcription by Snail1/LOXL2 during epithelial-to-mesenchymal transition. Mol Cell 52:746-757

Miotto B, Sagnier T, Berenger H, Bohmann D, Pradel J, Graba YJ (2006) Chameau HAT and DRpd3 HDAC function as antagonistic cofactors of JNK/AP-1-dependent transcription during Drosophila metamorphosis. Genes Dev 20:101-112

Okonechnikov K, Golosova O, Fursov M, the UGENE team (2012) UGENE: a unified bioinformatics toolkit. Bioinformatics 28:11661167

Phalke S, Nickel O, Walluscheck D, Hortig F, Onorati MC, Reuter G (2009) Retrotransposon silencing and telomere integrity in somatic cells of Drosophila depends on the cytosine-5 methyltransferase DNMT2. Nat Genet 41:696-702

Rea S, Eisenhaber F, O'Carroll D, Strahl BD, Sun Z-W, Schmid M, Opravil S, Mechtler K, Ponting CP, Allis CD, Jenuwein T (2000) Regulation of chromatin structure by site-specific histone $\mathrm{H} 3$ methyltransferases. Nature 406:593-599

Reuter G, Dorn R, Hoffmann H-J (1982a) Butyrate sensitive suppressor of position-effect variegation mutations in Drosophila melanogaster. Mol Gen Genet 188:480-485

Reuter G, Werner W, Hoffmann H-J (1982b) Mutants affecting positioneffect heterochromatinization in Drosophila melanogaster. Chromosoma 85:539-551

Reuter G, Dorn R, Wustmann G, Friede B, Rauh G (1986) Third chromosome suppressor of position-effect variegation loci in Drosophila melanogaster. Mol Gen Genet 202: 481-487

Rothwell WF, Sullivan W (2000) Fluorescent analysis of Drosophila embryos. Sullivan W, Ashburner M, Hawley RS (eds) Drosophila protocols. Cold Spring Harbor (New York), Cold Spring Harbor Laboratory Press 141-157

Rudolph T, Yonezawa M, Lein S, Heidrich K, Kubicek S, Schäfer C, Phalke S, Walther M, Schmidt A, Jenuwein et al (2007) Heterochromatin formation in Drosophila is initiated through active removal of H3K4 methylation by the LSD1 homolog SU(VAR)3-3. Mol Cell 26:103-115

Ryder E, Ashburner M, Bautista-Llacer R, Drummond J, Webster J, Gubb D, Johnson G, Morley T, Sang Chan Y, Blows F et al (2007) The DrosDel deletion set: a Drosophila genome-wide chromosomal deficiency resource. Genetics 167:797-813

Sasai N, Kato Y, Kimura G, Takeuchi T, Yamaguchi M (2007) The Drosophila jumonji gene encodes a JmjC-containing nuclear protein that is required for metamorphosis. FEBS J 274:6139-6151

Schotta G, Ebert A, Krauss V, Fischer A, Hoffmann J, Rea S, Jenuwein T, Dorn R, Reuter G (2002) Central role of Drosophila SU(VAR)3-9 in histone H3-K9 methylation and heterochromatic gene silencing. EMBO J 21:1121-1131

Schotta G, Lachner M, Sarma K, Ebert A, Sengupta R, Reuter G, Reinberg D, Jenuwein T (2004) A silencing pathway to induce H3-K9 and H4-K20 tri-methylation at constitutive heterochromatin. Genes Dev 18:1251-1262

Seller CA, Cho C-Y, O'Farrell PH (2019) Rapid embryonic cell cycles defer the establishment of heterochromatin by eggless/SetDB1 in Drosophila. Genes Dev 33:403-417

Seum C, Reo E, Peng H, Rauscher FJ III, Spierer P, Bontron S (2007) Drosophila SETDB1 is required for chromosome 4 silencing. PLoS Genet 3:e76. https://doi.org/10.1371/journal.pgen.0030076
Shcherbata HR, Althauser C, Findley SD, Ruohola-Baker H (2004) The mitotic-to-endocycle switch in Drosophila follicle cells is executed by notch-dependent regulation of G1/S, G2/M and M/G1 cell-cycle transitions. Development 131:3169-3181

Shermoen AW, McCleland ML (2014) Developmental control of late replication and S phase length. Curr Biol 24:R144-R145. https:// doi.org/10.1016/j.cub.2014.01.023

Silver LM, Wu CE, Elgin SC (1978) Immunofluorescent techniques in the analysis of chromosomal proteins. Methods Cell Biol 18:151-167

Sinclair DA, Ruddell AA, Brock JK, Clegg NJ, Lloyd VK, Grigliatti TA (1992) A cytogenetic and genetic characterization of a group of closely linked second chromosome mutations that suppress position-effect variegation in Drosophila melanogaster. Genetics 130:333-344

Soufi A, Donahue G, Zaret KS (2012) Facilitators and impediments of the pluripotency reprogramming factors initial engagement with the genome. Cell 151:994-1004

Sugiyama T, Cam HP, Sugiyama R, Noma K, Zofall M, Kobayashi R, Grewal SIS (2007) SHREC, an effector complex for heterochromatic transcriptional silencing. Cell 128:491-504

Szabad J, Reuter G, Schröder MB (1988) The effect of two mutations connected with chromatin functions on female germ-line cells of Drosophila. Mol Gen Genet 211:56-62

Tartof KD, Hobbs C, Jones M (1984) A structural basis for variegating position effects. Cell 37:869-878

Tie F, Banerjee R, Stratton CA, Prasad-Sinha J, Stepanik V, Zlobin A, Diaz MO, Scacheri PC, Harte PJ (2009) CBP-mediated acetylation of histone H3 lysine 27 antagonizes Drosophila Polycomb silencing. Development 136:3131-3141

Ting DT, Lipson D, Paul S, Brannigan BW, Akhavanfard S, Coffman EJ, Contino G, Deshpande V, Lafrate AJ, Letovsky S et al (2011) Aberrant overexpression of satellite repeats in pancreatic and other epithelial cancers. Science 331:593-596

Tschiersch B, Hofmann A, Krauss V, Dorn R, Korge G, Reuter G (1994) The protein encoded by the Drosophila position effect variegation suppressor gene $\mathrm{Su}$ (var) 3-9 combines domains of antagonistic regulators of homeotic gene complexes. EMBO J 13:3822-3831

Tzeng TY, Lee CH, Chan LW, Shen CK (2007) Epigenetic regulation of the Drosophila chromosome 4 by the histone H3K9 methyltransferase dSETDB1. Proc Natl Acad Sci U S A 90:11376-11380

Wang C, Li Y, Cai W, Bao X, Girton J, Johansen J, Johansen KM (2014) Histone H3S10 phosphorylation by the JIL-1 kinase in pericentric heterochromatin and on the 4th chromosome creates a composite H3S10phK9me2 epigenetic mark. Chromosoma 123:273-280

Watts BR, Wittmann S, Wery M, Gautier C, Kus K, Birot A, Heo D-H, Kilchert C, Morillon A, Vasiljeva L (2018) Histone deacetylation promotes transcriptional silencing at facultative heterochromatin. Nucl Acids Res 46:5426-5440

Weiler KS (2007) E(var)3-9 of Drosophila melanogaster encodes a zinc finger protein. Genetics 177:167-178

Yamada T, Fischle W, Sugiyama T, Allis CD, Grewal SIS (2005) The nucleation and maintenance of heterochromatin by a histone deacetylase in fission yeast. Mol Cell 20:173-185

Yuan K, O'Farrell PH (2016) TALE-light imaging reveals maternally guided, H3K9me2/3-independent emergence of functional heterochromatin in Drosophila embryos. Genes Dev 30:579-593

Yuan K, Shermoen AW, O'Farrell PH (2014) Illuminating DNA replication during Drosophila development using TALE-lights. Curr Biol 24:R144-R145

Yuan K, Seller CA, Shermoen AW, O'Farrell PH (2016) Timing the Drosophila mid-blastula transition: a cell cycle-centered view. Trends Genet 32:496-507

Publisher's note Springer Nature remains neutral with regard to jurisdictional claims in published maps and institutional affiliations. 